\title{
Electricity Generation from Defective Tomatoes
}

11 The United States faces a significant burden in treating 0.61 billion $\mathrm{kg}$ of defective

12 tomatoes (culls) every year. We present a proof-of-concept for generating electricity from

13 culled tomatoes in microbial-electrochemical systems (MESs). This study delineates

14 impedance behavior of the culled tomatoes in MESs and compares its impedance spectra

15 with that of soluble substrates (dextrose, acetate, and wastewater). A series of AC and DC 
22 Keywords: defective tomato; microbial-electrochemical system; wastewater; impedance;

23 voltammetry

\section{1. Introduction}

25 Tomato packinghouses in the Unites States (U.S.) generate $6.12 \times 10^{8} \mathrm{~kg}$ of culled 26 (defective) tomatoes every year. The culled tomatoes fail customer requirements for 27 firmness and color due to freezing traces and growth cracks; they have a stem over 3 inches 28 of length, anthracnose, mold, decay, gray wall, or virus mottling; and they have cloudy 29 spots, ghost spots, internal browning and sunscalds [1]. With U.S. tomato production 30 reaching as high as $1.53 \times 10^{9} \mathrm{~kg} /$ year $(\sim 81 \%$ production in CA, Al, FL, GA, NC, SC, TN, 31 and VA) [2], the packaging houses incur significant disposal costs. Similarly, processing 32 plants generate culls during washing, inspection, pulping, juice finishing, evaporation, 33 sterilization, packing, and storage (Fig. S1). A kilogram of processed tomatoes generates 20 34 grams of culls and 20 grams of peel and skin residues (Fig. S1). The packaging houses 35 often hire third-party vendors [3] to dispose of the culls, incurring significant transportation 36 costs [4].

37 Available biotechnologies are not designed to optimize energy production from 38 culled tomatoes [5]. Activated sludge processes are suited to diluted wastewater (WW); 39 they also require significant energy inputs ( 112 KW per million gallons of WW) [6]. The 40 land application of culls is not an attractive option [4] due to ever-increasing stringent 41 regulations [7]. On-site composting requires expensive equipment during site preparation $42[4,8,9]$, demands lengthy treatment periods, and poses odor and dust issues [10]. 43 Anaerobic digestion (AD) is an established technology for generating methane-rich biogas 
44 [11-14] but requires a purification step to recover methane. Dark fermentation generates

45 hydrogen-rich biogas [15], but requires a purification step for separating hydrogen [16].

46 Microbial electrochemical systems (MESs) support an array of engineering

47 applications [17, 18] including biosensors [19, 20], electrolysis [21], desalination [22],

48 reverse electrodialysis [23], and struvite production [24]. The use of solid organic wastes

49 (SOWs) (e.g. food waste [25], sludge [26], soybean residue and rice husk [27], leaves [28],

50 marine sediment [29], wheat straw [28]) as electron donors for MESs is well established

51 [30]. Specifically, in our previous study [31], we showed that tomato pomace is a viable

52 electron donor in microbial fuel cells. There are a fair number of impedance studies on the

53 use of pure substrates (e.g. lactate) [32], wastewater [33], and marine wastes [34] in

54 MESs. However, there is a notable paucity of literature investigating the impedance

55 behavior of SOW-based MESs [35, 36].

56 The overarching objective of this study was to demonstrate a proof-of-concept for

57 generating electricity from culled tomatoes. To our knowledge, there are no prior studies

58 that provide time-variant impedances to Faradaic processes related to oxidation of culled

59 tomatoes in MESs. We delineate the long-term oxidative behavior and impedance

60 contributions of the particulate fraction (i.e., peel \& seed) of the cull. We use a series of

61 DC techniques (voltammetry), AC techniques (electrochemical impedance analysis (EIS)),

62 and spectrophotometry tests (chemical oxygen demand (COD)) to compare oxidation

63 behavior of as is culls with its peel and seed (P\&S) and readily soluble substrates

64 including pure dextrose (represent monosaccharides in the cull), pure acetate (fermentation

65 product of dextrose), and municipal wastewater. We hypothesize that the indigenous redox 
66 shuttles (e.g. carotenoids, flavins, flavonoids) and nutrition-rich flesh in the cull promotes

67 its oxidation, while its peel \& seed impedes its degradation kinetics [37].

68 There are several reasons why the oxidation behavior of as is culls is different from

69 soluble substrates. First, the following indigenous nutritional compounds in culls serve an

70 excellent energy source for growth of anode-respiring bacteria (ARB) in MESs: sucrose

$71 \quad\left(\Delta \mathrm{G}_{\mathrm{f}}^{0}=-1551.8 \mathrm{~kJ} / \mathrm{mole}\right)$, amino acids $\left(\Delta \mathrm{G}_{\mathrm{f}}^{0}=-763 \mathrm{~kJ} / \mathrm{mole}\right)$, oleic acid $\left(\Delta \mathrm{G}_{\mathrm{f}}^{0}=-50.88\right.$

$72 \mathrm{~kJ} / \mathrm{mole})$, palmitic acid $\left(\Delta \mathrm{G}_{\mathrm{f}}^{0}=-305 \mathrm{~kJ} /\right.$ mole $)$, stearic acid $\left(\Delta \mathrm{G}_{\mathrm{f}}^{0}=-50.88 \mathrm{~kJ} / \mathrm{mole}\right)$ and

73 linoleic acid $\left(\Delta \mathrm{G}_{\mathrm{f}}^{0}=-50.88 \mathrm{~kJ} / \mathrm{mole}\right)$ [38-41] (Table $\left.1 \mathrm{~b}\right)$. The skin and seed in the culls are

74 rich in micronutrients $(\mathrm{Cu}, \mathrm{Mn}, \mathrm{Ni}$, and $\mathrm{Zn})$ and macronutrients (Fe, Na, K, Ca) (Table 1a).

75 Tomatoes contain a variety of redox-active species [42, 43] such as carotenoids,

76 kampferol, malvin, myricetin, naringenin, naringin, petunidin, quercetin, and riboflavin

77 (Table 1b), which qualify as redox-active mediators in MESs for following reasons [44-

78 52]; they are characterized by: i) fast redox equilibration; ii) fully reversible reactions

79 (oxidized and reduced form of mediators do not yield irreversible reactions); iii)

80 experimentally established standard redox potentials; and iv) defined stoichiometry with

81 respect to the number of electron and protons during Faradaic processes. These mediators

82 catalyze extracellular electron transfer from ARBs to solid electrode in MESs. For

83 example, flavins $\left(\mathrm{E}_{0 \mathrm{FMN} / \mathrm{FMNH}}^{\prime}=-190 \mathrm{mV}\right.$ vs. SHE) are known to promote extracellular

84 electron transport capabilities of Shewanella Oneidensis MR1 [31]. Quercetin in tomatoes

85 exhibits electrochemical activity in aqueous electrolytes under a range of $\mathrm{pH}$ conditions

$86(\mathrm{pH}=4.3-11.2)$ [53]. Table $1 \mathrm{~b}$ provides a list of indigenous species in tomatoes, their

87 standard redox potential, and the number of electrons transferred during the redox 88 processes. 
Second, the peel and skin components of as is cull represent complex, particulate

90 COD (pCOD) matter that is known for its sluggish disintegration and hydrolysis kinetics

91 in biological systems. The MESs using the pCOD will suffer from the diffusion-limited

92 performance. Third, unlike municipal wastewater, the culls are more beneficial in MESs

93 due to their carbohydrate content (39 mg per gram of cull), low $\mathrm{pH}$, and high electrical

94 conductivity [54]. Furthermore, as explained earlier, unlike wastewater, culled tomatoes

95 contain redox-active carotenoids and flavonoid molecules (Table 1b). From a large-scale

96 treatment perspective, it is important to distinguish electrical performance of culls from

97 municipal wastewater.

98 Finally, the dextrose in culled tomatoes will promote the growth of methanogens.

99 Based on the above background, it becomes important to distinguish the polarization

100 response and impedance behavior of MESs with culls from the peel \& seed, the

101 fermentable (dextrose) and non-fermentable (acetate) substrates, and the municipal

102 wastewater. At the typical low current densities $\left(<10 \mathrm{~A} / \mathrm{m}^{2}\right)$ [55] encountered in MESs, we

103 anticipate as is culls to outperform seed \& skin and municipal wastewater. While

104 counterintuitive, we have also observed that the culled tomatoes outperform pure

105 chemicals (dextrose and acetate). Since the peel and seed are integral components of the

106 cull, we performed a 125 days long, EIS study to distinguish the temporal impedance

107 contributions (charge transfer resistance, ohmic, and diffusion limitations) of the peel and 108 skin to the oxidation of culls.

109

\section{2. Materials \& Methods}


111 2.1. Reactor configuration and Electrolyte Composition

112 We used a two-chambered microbial fuel cell [1] as a laboratory model for

113 microbial electrochemical systems (MESs). A hydrated Ultrex membrane provided a

114 hydraulic separation between the anode and cathode chambers. The $100 \mathrm{mM}$ ferricyanide

115 (in $50 \mathrm{mM}$ phosphate buffer) was used as the electron acceptor in the cathode. The reactor

116 design is similar to that in our earlier study [31] (Details in Fig. S2). The tests were carried

117 out in five identical MESs varying in the type of carbon substrate 1) as is cull, 2) peel \&

118 seed, 3) dextrose, 4) acetate, and 5) municipal wastewater (Table S1). The five test MESs

119 are herein referred as CULL, P\&S, DEX, ACE, and WW. A MES that lacked a carbon

120 source was run simultaneously to provide a control. The anode was inoculated with an

121 enriched mixture of electrochemically active microbial population described in our earlier

122 study [31]. We evaluated the performance of five test MESs in 14 consecutive cycles

123 extended during 125 days of fed-batch operation. We eliminated planktonic microbes at the

124 end of each cycle by draining anolyte and gently washing the anode with $50 \mathrm{mM}$

125 phosphate. We used the following minimal media to prepare the anolyte: $\mathrm{NH}_{4} \mathrm{Cl}, 1.24 \mathrm{~g} / \mathrm{L}$;

$126 \mathrm{KCl}, 0.52 \mathrm{~g} / \mathrm{L} ; \mathrm{NaH}_{2} \mathrm{PO}_{4} \cdot \mathrm{H} 2 \mathrm{O}, 2.45 \mathrm{~g} \mathrm{~L}^{-1} ; \mathrm{Na}_{2} \mathrm{HPO}_{4} 7 \mathrm{H}_{2} \mathrm{O}, 4.576 \mathrm{~g} / \mathrm{L}$; vitamin mix, 10

$127 \mathrm{ml} / \mathrm{L}$; and trace minerals, $10 \mathrm{ml} / \mathrm{L}$. The anolyte in test MESs was obtained by modifying the

128 minimal media with carbon substrates (Table S1).

129 2.1.1. CULL: Fresh tomato culls obtained from Immokalee farm, Naples, FL, were

130 quartered and boiled in distilled water for 5 minutes; cooled at $11{ }^{\circ} \mathrm{C}$ for 10 minutes; placed

131 on an aluminum foil; heat-dried at $60{ }^{\circ} \mathrm{C}$ for 18 hours. $9.7 \mathrm{mg}$ of powdered cull was mixed

132 with one litre of minimal media. 
133 2.1.2. P\&S: The cull was quartered and boiled in distilled water for 5 minutes and cooled

134 at $11{ }^{\mathrm{O}} \mathrm{C}$ for 10 minutes. The skin and seeds were manually separated from the dried cull

135 and heated at $60{ }^{\circ} \mathrm{C}$ for 18 hours. The skin and seed were combined in a ratio of 3:4 (w/w)

136 and mixed in minimal media to achieve $9.7 \mathrm{mg} / \mathrm{L}$.

137 2.1.3. DEX, ACE, and WW: The DEX used $1 \mathrm{~g} / \mathrm{L}$ of dextrose $(180.16 \mathrm{~g} / \mathrm{mol}$; melting 138 point $146{ }^{\circ} \mathrm{C}$; CAS Number: 50-99-7, G8270, Sigma Aldrich) [56] and ACE used 1 g/L of 139 acetate (59.04 g/mol; MP $16.6^{\circ} \mathrm{C}$; CAS Number: 127-09-3, S2889, Sigma Aldrich [57]).

140 The WW used primary clarifier effluent from Rapid City wastewater treatment facility, SD 141 (COD concentration approx. 828mg/L, $\mathrm{pH} 7 \pm 0.7$ ). The initial $\mathrm{pH}$ values for anolyte in both 142 DEX and ACE ranged from 6.9-7.1.

143 2.2. Analytical Methods, Data acquisition \& AC impedance

$1445 \mathrm{~mL}$ of anolyte was periodically collected using a gastight syringe to measure its

$145 \mathrm{pH}$ (Cole-Palmer probe) and soluble Chemical Oxygen Demand (sCOD) (Method 5220 146 Hach COD system). Voltage data was acquired with a DAQ/54 module configured with an 147 external resistor. The polarization data was obtained for test MESs on day 1, 45, 59, 74, 86, 148 and 105 by recording the steady state voltage values at a specified value of external resistor. 149 The EIS for CULL, P\&S, and DEX was performed with a CHI electrochemical 150 workstation. The ACE and WW were evaluated with a Gamry600 workstation. The EIS 151 tests were performed at open circuit potential using an AC signal with an amplitude of \pm 10 $152 \mathrm{mV}$ (vs. $\mathrm{Ag} / \mathrm{AgCl}$ ) and the EIS spectra were obtained in the frequency range of 10000 to $153 \quad 0.01 \mathrm{~Hz}$. The EIS tests used the anode as the working electrode and the cathode as counter 154 and reference electrodes. The temporal EIS responses for CULL and P\&S were recorded on 155 days $1,16,21,45,72,88,103$, and 107 . The solution resistance was interpreted from the 
156 Nyquist plot as the real axis value at the high frequency intercept. The real axis value at the

157 low frequency intercept of Nyquist plot corresponds to the sum of the polarization 158 resistance and the solution resistance.

159 2.3. Cyclic Voltammetry (CV)

160 A CV technique was used to analyze CULL, ACE, and WW using the anode as the 161 working electrode, cathode as the counter electrode respectively, and $\mathrm{Ag} / \mathrm{AgCl}$ system as 162 reference electrode. We scanned the working electrode in a potential region of -0.8 and 0.8 $163 \mathrm{~V}$ at a sweep rate of $10 \mathrm{mV} / \mathrm{s}$ (vs. $\mathrm{Ag} / \mathrm{AgCl}$ ). The Randles Sevcik equation [58] was used to 164 analyze the cyclic voltammograms for CULL, ACE, and WW.

$165 \quad i_{p}=\left(2.687 * 10^{5}\right) * n^{\frac{3}{2}} * v^{\frac{1}{2}} * D^{\frac{1}{2}} * A^{*} C$

166

167 Where $i_{p}$ is peak current, $n$ is number of electrons transferred, $A$ is electrode area, $F$ is

168 Faraday Constant, D is diffusion coefficient of the species, $\mathrm{v}$ is scan rate, $\mathrm{C}$ is bulk

169 concentration of the species and $\mathrm{T}$ is temperature.

170

$171 \quad 3.0$ Results and Discussion

172 The performance data for CULL, P\&S, DEX, ACE, and WW are summarized in Table S2.

173 3.1. Unique oxidation behavior in CULL and P\&S compared to soluble substrates

174 Fig. 1-9 compares the oxidation behavior for the cull and the soluble substrates.

175 Unlike the DEX, ACE, and WW (Fig. 1b), the CULL develops a reddish-orange color due 176 to the carotenoids (e.g. lycopene [55] and redox-active $\beta$-carotene [31]). The CULL 177 promotes the formation of two distinct phases (Fig. 1a): i) the particulate phase (the peel \& 178 seed) characterized with pCOD and ii) a clear aqueous phase dominated by sCOD from the 
179 flesh (tissue, columella, pericarp, vascular bundle, and locular activity). Given the slow180 kinetics of pCOD oxidation and the sluggish disintegration and hydrolysis reactions [59-61] 181 that characterize the $\mathrm{P} \& \mathrm{~S}$ substrate, we can better understand the inferior performance of 182 P\&S compared to CULL (Fig. 1-9). As expected, the DEX, ACE, and WW did not yield 183 any color nor did the solid sludge (Fig. 1b).

184 In our earlier study [31] on the EIS analysis of the microbial fuel cell with the peel 185 and seed (P\&S) of culled tomatoes as the sole carbon source, we have observed the three 186 distinct time constants in the three different frequency regions of the Bode phase angle 187 plots: i) a low frequency region (LFR) peak representing the charge transfer resistance 188 (CTR) to the slow kinetics related to the oxidation of peel and seed; ii) a high frequency 189 region (HFR) peak due to the fast redox processes associated with metallic salts in the 190 anolyte; and iii) a mid-to-low frequency region (MFR) peak attributed to the CTR [32] of 191 the Faradaic processes related to indigenous mediators in the tomato (Table 1b). Further, 192 these MFR peaks showed a facile response to the changes in the bias potential ( $-50 \mathrm{mV}$ to $193450 \mathrm{mV}$ (vs. $\mathrm{Ag} / \mathrm{AgCl}$ )), confirming the influence of the indigenous mediators on the 194 Faradaic processes in tomato systems [31]. In contrast to the multiple time constants 195 observed in the EIS spectra for the peel and seed systems [31], contemporary EIS studies 196 on the MESs with wastewater [62] and pure substrates [63] have reported a single time 197 constant in Bode phase angle plots.

198 Though we observed the three time constants (including the MFR peak) in the 199 Bode phase angle plots for CULLs, they were less dominant (compared to that in our earlier 200 study with peel and seed [31]) (Fig. 1C). Further, the EIS results for the CULL, for 201 different cycles of the fed-batch operation shown in Fig. 2, did not yield a consistent 
202 impedance spectra pattern in each of the three frequency regions (e.g., corresponding 203 frequencies for the phase angle minima $\left(f_{\min }\right)$ and the maxima $\left.\left(f_{\max }\right)\right)$. Further studies are 204 required to evaluate if the monosaccharide components in the flesh of the culled tomatoes 205 (See Table 1b) delay or diminish the time constants in the LFR and MFR (compared to the 206 impedance spectra for peel \& seed) [31], especially for different values of the DC bias 207 potential, and in response to the biofilm history and the media replacement during the fed208 batch operation. Nevertheless, the CV results described in section 3.3 indicate a strong role 209 of the indigenous redox-active species (esp., flavonoids and carotenoids in Table 1b) on the 210 CULL performance.

211 Finally, as expected, the temporal profiles for sCOD consumption in the ACE and 212 WW followed a linear pattern and demonstrated a 92\% sCOD removal (Fig. 3b). However, 213 the sCOD profiles for CULL and P\&S followed a non-linear pattern (Fig. 3a). This is due 214 to the complex dynamics of pCOD--->sCOD conversion influenced by the synergistic 215 effects of the factors related to disintegration and hydrolysis kinetics, biofilm history, mass 216 transfer limitations, and electrical parameters. Further, the $\mathrm{sCOD}_{\text {initial }}$ for $\mathrm{DEX}, \mathrm{ACE}$, and 217 WW was manually adjusted to $1000 \mathrm{mg} / \mathrm{L}$ (Fig. 3b); the different mass inputs of the cull 218 and peel\&seed resulted in different $\mathrm{sCOD}_{\text {initial }}$ values for CULL (2000 mg/L) and P\&S 219 (3000 mg/L) (Fig. 3a). The sCOD removal efficiency in the DEX was less than 50\% and 220 this is due to the fact that the dextrose can be fermented to sCOD-bearing organic acids and 221 ethanol $[64,65]$.

222

223 3.2. Defective tomatoes are superior to pure chemicals 
The electrical performance of the P\&S was inferior to CULL (Fig. 2b, 2c, 4, S3;

225 Fig. 7, 8) throughout the hundred days of MES operation (Fig. S4). While counter-intuitive $226[30,66]$, the CULL has outperformed DEX and ACE that used pure substrates (open 227 circuit, Fig. 2a; closed-circuit, Fig. 2b,2c,S3). The average $\mathrm{OCV}_{\max }$ (vs. $\left.\mathrm{Ag} / \mathrm{AgCl}\right)$ for 228 CULL (0.71 V) is higher than P\&S (0.67 V), DEX (0.7 V), ACE (0.63 V), and WW (0.41 229 V). Considering that $\mathrm{P} \& \mathrm{~S}$ is characterized with the $\mathrm{pCOD}$, it is interesting to note that its 230 OCV is equivalent to CULL and DEX. One-way ANOVA analysis confirmed the absence 231 of statistically significant differences between the mean OCV for CULL, P\&S, and DEX $232(\mathrm{n}=22 ; \mathrm{P}$-value $=0.274>0.05, \mathrm{~F}=1.31 ;$ Bartlett's statistic $=0.9266, \mathrm{p}$-value $=0.629>0.05)$

233 (Table S3). As anticipated, the OCV in the ACE is lower than DEX and higher than WW.

234 Fig. 2b, 2C and S3 indicates identical start-up behavior of five test MESs (2400 data 235 points) under closed circuit conditions (load 1000 $\Omega$ ). The CULL, P\&S, and DEX exhibits 236 a lag of $70 \mathrm{~h}$ to register minimal electrical output, and additional $700 \mathrm{~h}$ to register 237 current $_{\max }$ CULL, $1.03 \mathrm{~A} / \mathrm{m}^{2}$; P\&S, $0.97 \mathrm{~A} / \mathrm{m}^{2}$; and DEX, $0.98 \mathrm{~A} / \mathrm{m}^{2}$ (Fig. 2, S3). However, 238 as shown in Fig. 4, 5, S4, the performance differences between test MESs are pronounced 239 at higher current densities. Given the identical reactor configuration, the variation in 240 polarization responses (Fig. 4, 5, S5, S6) is attributable to the differences in the oxidation 241 behavior of the carbon substrates. The polarization losses were ranked as:

$242 \mathrm{CULL}<\mathrm{DEX}<\mathrm{P} \& \mathrm{~S}<\mathrm{ACE}<\mathrm{WW}$; the corresponding power densities were in the order: 243 CULL $>$ DEX $>$ P\&S $>$ ACE $>$ WW (Fig. S5, S6, S7).

244 The bar plot in Fig. S4 compares the magnitude of power densities and current 245 densities for CULL, P\&S, and DEX. The CULL outperformed DEX during the fourteen 246 different cycles (Fig. S8): the peak current density $\left(1504 \mathrm{~mA} / \mathrm{m}^{2}\right)$ and peak power density 
$247\left(256.1 \mathrm{~mW} / \mathrm{m}^{2}\right)$ in the CULL was $56 \%$ and $55 \%$ higher than that in DEX (peak current 248 density: $964.3 \mathrm{~mA} / \mathrm{m}^{2}$, peak power density: $163.4 \mathrm{~mW} / \mathrm{m}^{2}$ ), respectively. Similarly, the 249 peak current density $\left(1504 \mathrm{~mA} / \mathrm{m}^{2}\right)$ and peak power density $\left(256.1 \mathrm{~mW} / \mathrm{m}^{2}\right)$ in CULL were $25038 \%$ and $20.5 \%$ higher than that in ACE $\left(1092.9 \mathrm{~mA} / \mathrm{m}^{2} ; 212.6 \mathrm{~mW} / \mathrm{m}^{2}\right)$, respectively (Fig.

$2514,5)$. The superior performance of CULL is attributed to its monosaccharides (3 grams of 252 sugar per gram of cull), and redox-active species (e.g. carotenoid, flavins, and quercetin) 253 characterized with high electron-transfer rates (Table 1b). The inferior performance of the 254 DEX is attributed to methanogens that thrive in glucose substrates and divert electron flux 255 towards reduced products (e.g. fatty acids) [65]. This observation is consistent with our 256 prior findings where glucose substrates yielded lower performance compared to the solid 257 algae [34].

3.3. Redox shuttles in CULL appears at a potential of $0.3 \mathrm{~V}$ higher potential than contemporary species

261 We have carried out CV studies to study the electrochemical behavior of plausible 262 mediators involved in the oxidation of culled tomatoes. As shown in Fig. 6, the biofilm263 coated anodes in the CULL exhibited non-sigmoidal voltammograms indicating a single 264 electron-transfer process [58]. This behavior is attributed to the indigenous, redox-active 265 carotenoids and flavonoids in tomatoes. As shown in Table $1 \mathrm{~b}$ and discussed in earlier 266 sections, these redox-active species [67-70] can serve as mediators to catalyze extracellular 267 electron transfer in ARBs. As shown in Fig. 6, the CULL exhibits oxidation and reduction 268 peaks at $0.255 \mathrm{~V}$ (vs. SHE) and $0.425 \mathrm{~V}$ (vs. SHE) respectively. The midpoint peak 269 potential (0.335 V vs. SHE) for CULL occurs at higher values (more positive) compared to 
270 ACE (-0.34 V vs. SHE). In fact, the peak potential for the CV in the CULL is $0.3 \mathrm{~V}$ higher

271 than that for contemporary MESs using Geobacter, R.palustris DX-1, and T.ferriacetica.

272 [31] The higher-potential-redox-active-species (HPRAS) in the CULL dominated the CVs

273 at all the tested scan rates (Fig. 6b). At a low-scan rate, the ratio of cathodic and anodic

274 peak currents $\left(\mathrm{i}_{\mathrm{pc}} / \mathrm{i}_{\mathrm{pa}}\right)$ in CULL was 1.56 indicating the quasi-reversible nature of the

275 HPRAS that undergoes structural reorganization without disrupting its molecular structure.

276 The peak potential of $0.33 \mathrm{~V}$ (vs. SHE) for HPRAS corresponds to quercetin compounds in

277 tomatoes (0.33 V vs. SHE) [71-74]. Quercetin is a bioactive flavonoid compound which

278 can yield one, two, three or even four anodic peaks in aqueous electrolytes [53].

279 The peak potential for HPRAS also overlaps with carotenoids (0.204- $0.449 \mathrm{~V}$ vs.

280 SHE) [75, 76]. Among the diverse range of carotenoids, lycopene and $\beta$-carotene are

281 primarily responsible for orange color in matured tomatoes [77, 78]. As shown in Fig. 1a,

282 we have observed a distinct reddish-orange color in anolyte media which can be attributed

283 to carotenoids [79] that are known to influence electron transfer processes [76]. For

284 example, an electrochemical study by Liu et al. [76], has delineated a series of

285 electrochemical parameters (oxidation potential, reaction rate constant, and kinetic

286 equilibrium constants) for 12 naturally occurring carotenoids, and confirmed that oxidation

287 peaks for carotenoids occur at lower potential compared with the reduction peaks. As

288 shown in Fig. 6b, we have observed anodic peaks at lower potential compared to cathodic

289 peaks (Fig. 6b), corroborating the presence of redox-active carotenoids in CULL-MESs.

290 Prior high-performance liquid chromatography (HPLC) studies have established the

291 presence of quercetin and carotenoid pigments (lycopene and $\beta$-carotene) in tomatoes [43,

292 80-82] (See Table 1b for details). Further studies are required to decipher the specific 
293 chemical characteristics of these HPRAS molecules. Nevertheless, the findings from DC

294 tests (Fig. 6a, 6b, and 6c) agree with those of AC tests (Fig. 1c, S9, S10; Fig. 7, 8) and

295 corroborate the role of indigenous redox mediators on Faradaic processes related to

296 oxidation of culled tomatoes. The redox mediators can be lost during the media

297 replacements in the fed-batch operation. However, it is critical to note that mediators are

298 indigenous to culled tomatoes-each new cycle in fed-batch operation will replenish the

299 mediators. Further, the start-up curves in Fig. 2 indicate the formation of resilient,

300 electrochemically active biofilm on the anode surface, indicating that these mediators can

301 also be accumulated in biofilms. Further studies are required to discern the relative

302 contribution of IRMs on electricity production.

303 Unlike CULL, the ACE exhibited redox peak at a lower voltage (-0.34 V vs. SHE)

304 corresponding to known electron acceptors such as ferredoxin (-0.398 vs. SHE) and

305 cytochrome OmcB (-0.19 V vs. SHE) [83-86]. For a $1 \mathrm{mv} / \mathrm{s}$ scan rate, the $\mathrm{i}_{\mathrm{pc}} / \mathrm{i}_{\mathrm{pa}}$ ratio for

306 ACE was close to unity suggesting the reversible nature of participating redox-active

307 species. This is an anticipated result, given the purity of the ACE compound compared with

308 the complex particulate nature of the defective tomatoes in the CULL. The WW exhibited a

309 mid-point peak at low potential (-0.19 V vs. SHE) whose peak current ( $\left.\mathrm{i}_{\mathrm{p}}\right)$ (both anodic and

310 cathodic sweeps) was an order of magnitude lower than the CULL (Fig. 6a-c).

311 The $\mathrm{i}_{\mathrm{pc}} \mathrm{i}_{\mathrm{pa}}$ ratio for both CULL and ACE decreased with increasing scan rates (Fig.

312 6b). The slow scan rate provides adequate time for redox-active species to participate in

313 electrochemical reactions and contribute to higher faradic current (Fig. 6a). As scan rates

314 grow faster and the voltage range scanned is wider, the diffusion rates decreased and the

315 separation between the anodic and cathodic peak potentials $\left(\Delta \mathrm{E}_{\mathrm{p}}\right)$ increased (Fig. 6b). The 
316 increase in $\Delta \mathrm{E}_{\mathrm{p}}$ with increasing scan rate is attributed to the charge transfer limitations

317 induced by the electrostatic factors, chemical interaction between electrolyte ions and 318 anode and interactions of redox couples [87]. The Randles-Sevcik equation (Eq. 1) was

319 used to confirm that the values of peak current $\left(I_{p}\right)$ are directly proportional to the $v^{1 / 2}$ 320 (square root of scan rate) indicating the diffusion-controlled, current regime in the CULL $321\left(\mathrm{n}=8 ; \mathrm{r}^{2}=0.85 ; \mathrm{F}=12.4 ; \mathrm{p}=0.77\right)$ and $\operatorname{ACE}\left(\mathrm{n}=20 ; \mathrm{r}^{2}=0.81 ; \mathrm{F}=35 ; \mathrm{p}=0.0005\right)$. However, the 322 slope $(0.00135)$ of the I- $\mathrm{v}^{1 / 2}$ curve in ACE is 27 fold higher than the CULL (slope $=$ 323 0.00005), indicating a higher transfer coefficient of the participating redox-shuttles in the 324 ACE. The differences in the magnitudes for the slopes can be attributed to differences in 325 the diffusion coefficient (D) of their respective redox couples. The easy electrocatalytic 326 behavior of the redox shuttles and the higher peak current $\left(i_{p}\right)$ in ACE can be explained by 327 the fact that the bio-kinetic rates for the acetate oxidation is significantly higher than that 328 for the pCOD oxidation.

3303.4 The higher impedance in $\mathrm{P} \& \mathrm{~S}$ induces its skewed polarization behavior at higher 331 currents

332 The $\mathrm{P} \& \mathrm{~S}$ exhibited a skewed polarization behavior (i.e. concave-shaped power 333 density curves) on Day 45, 59, and 74 (Fig. 4, S5), while the CULL yielded a smoother 334 polarization response (Fig. 4, S5). The recalcitrant behavior of the pCOD in the peel and 335 seed limits the ability of P\&S to meet the larger over potential required at higher current 336 densities, while the readily available sCOD from the flesh sustains the performance of 337 CULL at all the current densities. The long-term EIS studies have corroborated the 
338 dominant impedance behavior of the peel \& seed at a range of frequencies $(10 \mathrm{kHz}-10$ $339 \mathrm{mHz}$ ) and time-scales (1-107 days) (Fig. 8).

340 The operational changes (e.g. media replacements) have resulted in the diverse 341 impedance behavior of both the P\&S and CULL (see the diverse shapes for the bell-shaped

342 curves in the Nyquist plots; Fig. 8) throughout the 103 days of fed-batch operation. For 343 instance, the Nyquist plots for Day 21 and Day 103 yielded three distinct loops; Day 16 and 344 Day 72 yielded two incomplete semicircles; and the Day 45 and Day 107 yielded a single 345 time constant but characterized with the diffusion resistance (extended arc in low-frequency 346 region). It is therefore not feasible to identify a common model (e.g. Randle's circuit) that 347 fits the entire range of the impedance data shown for 106 days (Fig. 8). Instead of using the 348 electrical equivalent circuit fitting method, we have obtained the polarization resistance $349\left(\mathrm{R}_{\mathrm{polz}}\right)$ as the real axis value at low frequency intercept.

350 We found that the $\mathrm{R}_{\text {polz }}$ for the P\&S was $17-39 \%$ greater than the CULL during all 351 the time scales (Fig. 9). For example, the $R_{\text {polz }}$ in the $P \& S$ was 1.7 fold higher than the 352 CULL on day 45 . The one-tailed t-test (95\% confidence interval) confirms statistically 353 significant differences between the $\mathrm{R}_{\mathrm{polz}}$ for P\&S and the CULL (paired test: $\mathrm{p}$-value $3540.0245 ; \mathrm{t}=2.213 ; \mathrm{n}=11$; mean of difference $=6.674, \mathrm{R}^{2}=0.3081$ ). The EIS analysis indicates 355 that the peel \& seed will impede the oxidation of the culls at higher current densities. We 356 did not observe significant differences in the $R_{\text {ohm }}$ in five test MESs (Fig. 7) (One-way 357 ANOVA analysis; $\mathrm{n}=12$; P-value $=0.1375>0.05, \mathrm{~F}=2.109$; Corrected Bartlett's statistic $358=1.647 ; \mathrm{p}$-value $=0.439>0.05)$. 
We demonstrate the feasibility of generating electricity from defective tomatoes.

362 The performance of culled tomatoes was equivalent, or better than that of pure chemicals.

363 For example, the polarization resistance in optimized CULL was 10-40\% lower than the

364 DEX. The peak power densities in the CULL were 1.5 fold higher than the DEX and 1.3

365 times higher than the ACE. Our studies suggest that performance of CULL will be

366 impeded at higher current densities due to sluggish oxidation kinetics of its particulate

367 matter (peel and seed) in culled tomatoes. Nonetheless, the exceptional nutritional

368 components (carbohydrates, amino acids) and redox-active species (flavonoids and

369 carotenoids) in culled tomatoes render it an attractive feedstock for electricity production.

370 Unlike typical solid wastes such as food scraps, the culled tomatoes are available

371 throughout the year in diverse geographical locations, often with a well-defined

372 composition, enabling monoculture-based, large-scale electricity production.

374 Acknowledgements This study was in part supported by NASA (\# NNX13AB25A), EPRI, 375 NSF (\#1454102), and the ORSP at FGCU.

377 Supporting Information Mass balance for culls in Fig. S1. Reactor Design details in Fig.

378 S2. Start-up data for DEX, WW, and ACE in Fig. S3. Bar plots for peak power in Fig. S4.

379 Temporal performance of CULL and P\&S in Fig. S5. Temporal performance of DEX, 380 ACE, and WW in Fig. S6. Comparative performance of CULL and ACE in Fig.S7. 381 Temporal performance of CULL and DEX in Fig. S8. Bode phase angle plots for WW, 382 DEX and ACE in Fig. S9 and Fig. S10. Table S1 and S2 presents experimental design and 
results respectively. Table S3 describes one-way ANOVA analysis of temporal OCV values

in CULL, DEX, and ACE.

\section{List of Figures}

Fig. 1. (A) Photograph of the reddish-orange anolyte in MES with culled tomatoes. (B) Photograph of anolyte with readily soluble substrates (acetate in this case). (C) Bode phase angle plots for MESs with cull (green squares, $\mathbf{a}$ ) and peel\&seed (blue triangles, $\boldsymbol{\Delta}$ )

390 (Biofilm age $~ 100$ days)

391 (NOTE: See Fig. S1. for Bode phase angle plots for wastewater, dextrose, and acetate)

Fig. 2 (A) Steady state OCV response during 3000 hours of continuous fed-batch operation (Green line $-\longrightarrow$ - Cull, Blue line $-\mathbf{A -}$ - peel \& seed, red line $-\bullet-$ - dextrose, black line cull under closed circuit (C) steady state electrical performance of peel \& seed (NOTE: $L *_{-}$Lag time, $S *^{*}$ Start output, $M *^{*}$ Maximum output. See Fig. S3. for start-up of MESs with soluble substrates (dextrose, acetate, and municipal wastewater).

Fig. 3. (A) Remaining chemical Oxygen Demand (sCOD) in MESs with solid substrates (cull (green squares $=-$ ) and peel \&seed (blue triangles - ). (B) sCOD remaining in MESs with wastewater (brown diamonds -- ), dextrose ( red circles $-\bullet$ ), and acetate (black squares $\square$ ) $(\mathrm{SD}<5 \%$; $=3$ )

Fig. 4. Temporal data for power densities and polarization in MESs with two solid substrates (culls (green squares $=-$ ) and peel \& seed (blue triangles $=$ )

NOTE: Media replacements were performed on Days 12, 27, 43,47, 53, 60, 67, 74, 84, 89, 95, and 103. See Fig. S5 for details.

Fig. 5. Temporal data for power densities and polarization in MESs with three soluble substrates (dextrose (red circles $-\bullet$ ), acetate (blue diamonds - ), and wastewater (black dotted line - - - )

NOTE: Media replacements were performed on Days 12, 27, 43,47, 53, 60, 67, 74, 84, 89, 95, and 103. See Fig. S6 for details.

Fig. 6. A) Cyclic voltammograms for as is culls (blue solid line - - ), acetate (purple dotted line - - - ), and soluble chemical oxygen demand in municipal wastewater (dotted brown line $=--$ ) B) Cyclic voltammograms with varying scan rates for three test MESs (blue line - - $1 \mathrm{mv} / \mathrm{s}$, red line - - 5mv/s, green line - $10 \mathrm{mv} / \mathrm{s}$, purple line - - $50 \mathrm{mv} / \mathrm{s}$ ) C) Peak current against the square root of the scan rate for three test MESs (solid circles, cull, - acetate and -wastewater) represent measured value and the black solid line represents fitted data). The CVs were generated after 365 days of fed-batch operation. Prior 
423 to obtaining CVs, the anolyte was totally drained, and washed with phosphate buffer two 424 times.

425

426

427

428

429

430

431

432

433

434

435

436

437

438

439

440

441

442

443

444

445

446
Fig. 7. Nyquist plots for MESs with wastewater (brown diamonds $=$ ), dextrose (red circles $-\bullet-$ ), acetate (purple cross $\leftarrow$ ), peel \& seed (blue squares $-\square-$ ), and as is solid culls (green triangles -- ). Inset graph shows a clear view of the high frequency region.

Fig. 8. Comparative Nyquist responses for MES with peel and seed (blue triangles $-\mathbf{-}-$ ), and cull (green squares-m), for 100 days of fed-batch operation. AC signal: Frequency = $10 \mathrm{kHz}-100 \mathrm{mHz}$; Amplitude $= \pm 10 \mathrm{mV}$. Impedance measurements were performed on a full cell configuration.

Fig. 9. Temporal changes in the ohmic losses (green bar, $\square$ ) and polarization losses (blue bar, $\square$ for: i) cull, ii) peel and seed, and iii) dextrose

\section{List of Tables}

Table 1a: Nutritional constituents in defective tomatoes and their role in microbial electrochemical systems

Table. 1b Redox-active species found in defective tomatoes, their standard reduction potential and number of electrons transferred to and from redox species 


\section{References}

448 [1] W. Manley, United States standards for grades of tomatoes for processing, US Dept. Agr. Mktg. Serv., Washington, DC, (1983).

450 [2] United States Deparment of Agriculture, 2014.

451 [3] E. Riggi, G. Avola, Fresh Tomato Packinghouses Waste as High added-value

452 Biosource, Resources, Conservation and Recycling, (2008) 96-106.

453 [4] G. Toor, M. Chahal, B. Santos, Solutions for Managing Tomato Culls in Florida

454 Tomato Packinghouses, University of Florida, Gainesville, FL., 2012.

455 [5] J.P. Sheets, L. Yang, X. Ge, Z. Wang, Y. Li, Beyond land application: Emerging

456 technologies for the treatment and reuse of anaerobically digested agricultural and food

457 waste, Waste Management, 44 (2015) 94-115.

458 [6] V. Gadhamshetty, N. Koratkar, Nano-engineered biocatalyst-electrode structures for

459 next generation microbial fuel cells, Nano Energy, 1 (2012) 3-5.

460 [7] M. Ribaudo, N. Gollehon, J. Agapoff, Land application of manure by animal feeding 461 operations: Is more land needed?, Journal of Soil and Water Conservation, (2003) 30-38.

462 [8] F. Fornes, D. Mendoza-Hernández, R. García-de-la-Fuente, M. Abad, R.M. Belda,

463 Composting versus vermicomposting: a comparative study of organic matter evolution

464 through straight and combined processes, Bioresource technology, 118 (2012) 296-305.

465 [9] M.J. Fernández-Gómez, R. Nogales, H. Insam, E. Romero, M. Goberna, Continuous-

466 feeding vermicomposting as a recycling management method to revalue tomato-fruit wastes

467 from greenhouse crops, Waste management, 30 (2010) 2461-2468.

468 [10] L.J. Sikora, Benefits and Drawbacks to Composting Organic By-Products, Beneficial

469 Co-Utilization of Agricultural, Municipal and Industrial by-Products, Springer Netherlands,

470 Beltsville, Maryland, U.S., 1998, pp. 69-77.

471 [11] F. Monnet, An Introduction to Anaerobic Digestion of Organic Wastes, Remade

472 Scotland, 2003.

473 [12] D.W. Williams, D. Schleef, A. Schuler, Anaerobic Digestion of Brewery Watewater

474 for Pollution Control and Energy, ASAE/CSAE-SCGR Annual International Meeting,

475 Sponsored by ASAE and CSAE-SCGR, Toronto, 1999.

476 [13] P.S. Calabrò, R. Greco, A. Evangelou, D. Komilis, Anaerobic digestion of tomato

477 processing waste: Effect of alkaline pretreatment, Journal of environmental management,

478163 (2015) 49-52.

479 [14] D. Nguyen, V. Gadhamshetty, S. Nitayavardhana, S.K. Khanal, Automatic process

480 control in anaerobic digestion technology: A critical review, Bioresource technology, 193

481 (2015) 513-522.

482 [15] V. Gadhamshetty, Y. Arudchelvam, N. Nirmalakhandan, D.C. Johnson, Modeling dark

483 fermentation for biohydrogen production: ADM1-based model vs. Gompertz model,

484 international journal of hydrogen energy, 35 (2010) 479-490.

485 [16] V. Gadhamshetty, D.C. Johnson, N. Nirmalakhandan, G.B. Smith, S. Deng, Dark and

486 acidic conditions for fermentative hydrogen production, International journal of hydrogen

487 energy, 34 (2009) 821-826.

488 [17] I.A. Ieropoulos, P. Ledezma, A. Stinchcombe, G. Papaharalabos, C. Melhuish, J.

489 Greenman, Waste to real energy: the first MFC powered mobile phone, Physical Chemistry

490 Chemical Physics, 15 (2013) 15312-15316. 
[18] V.G. Gude, B. Kokabian, V. Gadhamshetty, Beneficial bioelectrochemical systems for energy, water, and biomass production, Journal of Microbial \& Biochemical Technology,

4932013 (2013).

494 [19] S. Choi, J. Chae, Optimal biofilm formation and power generation in a micro-sized microbial fuel cell (MFC), Sensors and Actuators A: Physical, 195 (2013) 206-212. [20] J.E. Mink, R.M. Qaisi, B.E. Logan, M.M. Hussain, Energy harvesting from organic liquids in micro-sized microbial fuel cells, NPG Asia Materials, 6 (2014) e89.

498 [21] R.D. Cusick, B. Bryan, D.S. Parker, M.D. Merrill, M. Mehanna, P.D. Kiely, G. Liu, 499 B.E. Logan, Performance of a pilot-scale continuous flow microbial electrolysis cell fed winery wastewater, Applied microbiology and biotechnology, 89 (2011) 2053-2063. [22] N.A. Shehab, G.L. Amy, B.E. Logan, P.E. Saikaly, Enhanced water desalination efficiency in an air-cathode stacked microbial electrodeionization cell (SMEDIC), Journal of Membrane Science, 469 (2014) 364-370.

504 [23] H. Wang, Z.J. Ren, A comprehensive review of microbial electrochemical systems as a platform technology, Biotechnology advances, 31 (2013) 1796-1807. [24] R.D. Cusick, B.E. Logan, Phosphate recovery as struvite within a single chamber microbial electrolysis cell, Bioresource technology, 107 (2012) 110-115.

508 [25] K. Chandrasekhar, K. Amulya, S.V. Mohan, Solid phase bio-electrofermentation of food waste to harvest value-added products associated with waste remediation, Waste 510 Management, (2015).

511 [26] Z. Ge, F. Zhang, J. Grimaud, J. Hurst, Z. He, Long-term investigation of microbial fuel 512 cells treating primary sludge or digested sludge, Bioresource technology, 136 (2013) 509513514.

514 [27] C.-T. Wang, F.-Y. Liao, K.-S. Liu, Electrical analysis of compost solid phase

microbial fuel cell, International Journal of Hydrogen Energy, 38 (2013) 11124-11130. [28] T.-S. Song, D.-B. Wang, S. Han, X.-y. Wu, C.C. Zhou, Influence of biomass addition on electricity harvesting from solid phase microbial fuel cells, International Journal of Hydrogen Energy, 39 (2014) 1056-1062.

[29] N. Haque, S.H. Kwon, Characteristics of Electricity Production by Metallic and Nonmetallic Anodes Immersed in Mud Sediment Using Sediment Microbial Fuel Cell, 한국환경과학회지, 23 (2014) 1745-1753.

[30] B.E. Logan, M.J. Wallack, K.-Y. Kim, W. He, Y. Feng, P.E. Saikaly, Assessment of microbial fuel cell configurations and power densities, Environmental Science \& Technology Letters, 2 (2015) 206-214. [31] A. Fogg, V. Gadhamshetty, D. Franco, J. Wilder, S. Agapi, S. Komisar, Can a microbial fuel cell resist the oxidation of Tomato pomace?, Journal of Power Sources, 279 (2015) 781-790.

[32] R.P. Ramasamy, V. Gadhamshetty, L.J. Nadeau, G.R. Johnson, Impedance spectroscopy as a tool for non-intrusive detection of extracellular mediators in microbial fuel cells, Biotechnology and bioengineering, 104 (2009) 882-891. [33] D. Fangzhou, L. Zhenglong, Y. Shaoqiang, X. Beizhen, L. Hong, Electricity generation directly using human feces wastewater for life support system, Acta Astronautica, 68 (2011) 1537-1547. 
[34] V. Gadhamshetty, D. Belanger, C.J. Gardiner, A. Cummings, A. Hynes, Evaluation of Laminaria-based microbial fuel cells ( $\mathrm{LbMs}$ ) for electricity production, Bioresource technology, 127 (2013) 378-385.

[35] I. Danaee, M. Jafarian, F. Forouzandeh, F. Gobal, M. Mahjani, Impedance spectroscopy analysis of glucose electro-oxidation on Ni-modified glassy carbon electrode, Electrochimica Acta, 53 (2008) 6602-6609.

540 [36] R. Firstenberg-Eden, Electrical impedance method for determining microbial quality

of foods, Rapid Methods and Automation in Microbiology and Immunology, Springer1985, pp. 679-687.

[37] C.I. Torres, R. Krajmalnik-Brown, P. Parameswaran, A.K. Marcus, G. Wanger, Y.A. Gorby, B.E. Rittmann, Selecting anode-respiring bacteria based on anode potential:

phylogenetic, electrochemical, and microscopic characterization, Environmental science \& technology, 43 (2009) 9519-9524.

[38] Z.B. Maroulis, G.D. Saravacos, Food process design, CRC Press2003.

[39] L. Zong, S. Ramanathan, C.-C. Chen, System and method of modeling monoglycerides, diglycerides and triglycerides in biodiesel feedstock, Google Patents, 2013. [40] Al-Wandawi., Abdul-Rahman.M., K. Al-Shaikhly, . Tomato Processing Wastes as Essential Raw Materials Source, Journal of Agricultural and Food Chemistry, 33 (1985) 804-807.

[41] G. Rossini, G. Toscano, D. Duca, F. Corinaldesi, E.F. Pedretti, G. Riva, Analysis of the characteristics of the tomato manufacturing residues finalized to the energy recovery, Biomass and Bioenergy, 51 (2013) 177-182.

[42] X. Su, J. Xu, D. Rhodes, Y. Shen, W. Song, B. Katz, J. Tomich, W. Wang, Identification and quantification of anthocyanins in transgenic purple tomato, Food Chem, 202 (2016) 184-188.

[43] M. Biesaga, U. Ochnik, K. Pyrzynska, Fast analysis of prominent flavonoids in tomato using a monolithic column and isocratic HPLC, Journal of separation science, 32 (2009) 2835-2840.

[44] N. Arroyo-Currás, M.F. Videa, Electrochemical Study of Flavonoids in Acetonitrile: Structure-Activity Relationships, ECS Transactions, 29 (2010) 349-359. [45] G. Chen, X. Ma, F. Meng, G. Li, The electron transfer reactivity of kaempferol and its interaction with amino acid residues, Bioelectrochemistry, 72 (2008) 169-173. [46] L.M. Ignjatović, J.M. Dimitrić-Marković, D.A. Marković, J.M. Baranac, The spectroabsorptiometric and voltammetric behavior of malvin in buffered solutions and its antioxidant properties, Journal of the Serbian Chemical Society, 67 (2002) 53-60.

[47] D. Wu, S. Liu, H. Gao, J. Li, H. Liu, Q. Liang, Investigation on the electrochemical and spectra properties of myricetin, J Electrochem, 13 (2007) 29-34.

[48] M. Dhananjayulu, M. Sivaprasad, N. Sreedhar, Electrochemical oxidation behaviour of naringenin flavonoid using glassy carbon electrode modified with polyaniline based nanosensors, Journal of Science, 5 (2015) 54-59.

[49] P. Janeiro, A.M.O. Brett, Redox Behavior of Anthocyanins Present in Vitis vinifera L, Electroanalysis, 19 (2007) 1779-1786.

[50] M.E. Ghica, A.M.O. Brett, Electrochemical oxidation of rutin, Electroanalysis, 17 (2005) 313-318. 
[51] R.E. Blankenship, R. Feick, B.D. Bruce, C. Kirmaier, D. Holten, R.C. Fuller, Primary photochemistry in the facultative green photosynthetic bacterium Chloroflexus aurantiacus, Journal of cellular biochemistry, 22 (1983) 251-261.

581 [52] E. Reichart, D. Obendorf, Determination of naringin in grapefruit juice by cathodic stripping differential pulse voltammetry at the hanging mercury drop electrode, Analytica chimica acta, 360 (1998) 179-187. [53] R. Sokolova, S. Ramesova, I. Degano, M. Hromadova, M. Gal, J. Zabka, The oxidation of natural flavonoid quercetin, Chemical Communications, 48 (2012) 3433-3435. [54] M.K. Chahal, G.S. Toor, P. Nkedi-Kizza, B.M. Santos, Effect of tomato packinghouse wastewater properties on phosphorus and cation leaching in a spodosol, Journal of environmental quality, 40 (2011) 999-1009.

[55] A.P. Borole, C.Y. Hamilton, T.A. Vishnivetskaya, Enhancement in current density and energy conversion efficiency of 3-dimensional MFC anodes using pre-enriched consortium and continuous supply of electron donors, Bioresource technology, 102 (2011) 5098-5104. [56] Sigma Aldrich, G8270 SIGMA D-(+)-Glucose, 2016. [57] Sigma Aldrich, S2889 SIGMA-ALDRICH Sodium acetate, 2016. [58] J. Wang, Analytical electrochemistry, John Wiley \& Sons2006. [59] D.J. Batstone, J. Keller, I. Angelidaki, S. Kalyuzhnyi, S. Pavlostathis, A. Rozzi, W. Sanders, H. Siegrist, V. Vavilin, The IWA Anaerobic Digestion Model No 1(ADM 1), Water Science \& Technology, 45 (2002) 65-73.

[60] J. Boltz, The kinetics of particulate substrate utilization by bacterial films, (2005). [61] C.W. Teo, P.C.Y. Wong, Enzyme augmentation of an anaerobic membrane bioreactor treating sewage containing organic particulates, Water research, 48 (2014) 335-344.

[62] B. Wu, C. Feng, L. Huang, Z. Lv, D. Xie, C. Wei, Anode-biofilm electron transfer behavior and wastewater treatment under different operational modes of bioelectrochemical system, Bioresource technology, 157 (2014) 305-309.

[63] Z. Zhang, H. Wu, Photoelectrochemical reforming of biomass for hydrogen generation, RSC Advances, 4 (2014) 37395-37399.

[64] V.P. Dole, A relation between non-esterified fatty acids in plasma and the metabolism of glucose, Journal of Clinical Investigation, 35 (1956) 150.

[65] E.B. Sydney, C. Larroche, A.C. Novak, R. Nouaille, S.J. Sarma, S.K. Brar, L.A.J. Letti, V.T. Soccol, C.R. Soccol, Economic process to produce biohydrogen and volatile fatty acids by a mixed culture using vinasse from sugarcane ethanol industry as nutrient source, Bioresource technology, 159 (2014) 380-386.

[66] L. Xiao, Z. Ge, P. Kelly, F. Zhang, Z. He, Evaluation of normalized energy recovery (NER) in microbial fuel cells affected by reactor dimensions and substrates, Bioresource technology, 157 (2014) 77-83.

[67] N.V. Bhagavan, Medical biochemistry, Academic press2002.

[68] T. Matsui, Y. Kitagawa, M. Okumura, Y. Shigeta, Accurate Standard Hydrogen Electrode Potential and Applications to the Redox Potentials of Vitamin C and NAD/NADH, The Journal of Physical Chemistry A, 119 (2015) 369-376. [69] R.K. Thauer, K. Jungermann, K. Decker, Energy conservation in chemotrophic anaerobic bacteria, Bacteriological reviews, 41 (1977) 100.

[70] A. Kudo, H. Kato, I. Tsuji, Strategies for the development of visible-light-driven photocatalysts for water splitting, Chemistry Letters, 33 (2004) 1534-1539. 
[71] A. Cardenas-Robles, E. Martinez, I. Rendon-Alcantar, C. Frontana, L. GonzalezGutierrez, Development of an activated carbon-packed microbial bioelectrochemical system for azo dye degradation, Bioresource technology, 127 (2013) 37-43. [72] K.-J. Chae, M.-J. Choi, J.-W. Lee, K.-Y. Kim, I.S. Kim, Effect of different substrates on the performance, bacterial diversity, and bacterial viability in microbial fuel cells, Bioresource technology, 100 (2009) 3518-3525. [73] R. Sokolová, Š. Ramešová, I. Degano, M. Hromadová, M. Gál, J. Žabka, The oxidation of natural flavonoid quercetin, Chemical Communications, 48 (2012) 3433-3435. [74] E.S. Gil, R.O. Couto, Flavonoid electrochemistry: a review on the electroanalytical applications, Revista Brasileira de Farmacognosia, 23 (2013) 542-558.

[75] J. Bartz, C. Eayre, M. Mahovic, D. Concelmo, J. Brecht, S. Sargent, Chlorine concentration and the inoculation of tomato fruit in packinghouse dump tanks, Plant Disease, 85 (2001) 885-889.

638 [77] A.F. López Camelo, P.A. Gómez, Comparison of color indexes for tomato ripening, 639 Horticultura Brasileira, 22 (2004) 534-537.

640 [78] R. Arias, T.-C. Lee, L. Logendra, H. Janes, Correlation of lycopene measured by 641 HPLC with the $\mathrm{L}^{*}, \mathrm{a}^{*}, \mathrm{~b}^{*}$ color readings of a hydroponic tomato and the relationship of 642 maturity with color and lycopene content, Journal of Agricultural and Food Chemistry, 48 643 (2000) 1697-1702.

644 [79] A. Gastélum-Barrios, R.A. Bórquez-López, E. Rico-García, M. Toledano-Ayala, G.M. 645 Soto-Zarazúa, Tomato quality evaluation with image processing: A, African Journal of 646 Agricultural Research, 6 (2011) 3333-3339.

647 [80] Ö. Tokuşoğlu, M. Ünal, Z. Yıldırım, HPLC-UV and GC-MS characterization of the 648 flavonol aglycons quercetin, kaempferol, and myricetin in tomato pastes and other tomatobased products, Acta Chromatogr, 13 (2003) 196-207. [81] J.J.T. Gama, A.C. Tadiotti, C. Sylos, Comparison of carotenoid content in tomato, tomato pulp and ketchup by liquid chromatography, Alimentos e Nutrição Araraquara, 17 (2009) 353-358.

[82] H.G. Daood, G. Bencze, G. Palotás, Z. Pék, A. Sidikov, L. Helyes, HPLC analysis of carotenoids from tomatoes using cross-linked C18 column and MS detection, Journal of chromatographic science, (2013) bmt 139 .

[83] R. Cammack, K.K. Rao, C.P. Bargeron, K. Hutson, P. Andrew, L. Rogers, Midpoint redox potentials of plant and algal ferredoxins, Biochem. J, 168 (1977) 205-209.

[84] E.T. Smith, B. Feinberg, Redox properties of several bacterial ferredoxins using square wave voltammetry, Journal of Biological Chemistry, 265 (1990) 14371-14376.

666

[85] K. Fricke, F. Harnisch, U. Schröder, On the use of cyclic voltammetry for the study of anodic electron transfer in microbial fuel cells, Energy \& Environmental Science, 1 (2008) 144-147.

[86] T. Magnuson, N. Isoyama, A. Hodges-Myerson, G. DAVIDSON, M. Maroney, G. Geesey, D. Lovley, Isolation, characterization and gene sequence analysis of a membraneassociated $89 \mathrm{kDa}$ Fe (III) reducing cytochrome $\mathrm{c}$ from Geobacter sulfurreducens, Biochem. J, 359 (2001) 147-152. 
667 [87] A.C. de Sá, L.L. Paim, N.R. Stradiotto, Sugars Electrooxidation at Glassy Carbon 668 Electrode Decorate with Multi-Walled Carbon Nanotubes with Nickel Oxy-Hydroxide, Int.

669 J. Electrochem. Sci, 9 (2014) 7746-7762.

670 
$\mathbf{A}$


Fig. 1. (A) Photograph of the reddish-orange anolyte in MES with culled tomatoes. (B) Photograph of anolyte with readily soluble substrates (acetate in this case). (C) Bode phase angle plots for MESs with cull (green squares, $\square$ ) and peel\&seed (blue triangles, $\mathbf{\Delta}$ ) (Biofilm age $\sim 100$ days)

(NOTE: See Fig. S1. for Bode phase angle plots for wastewater, dextrose, and acetate) 
A
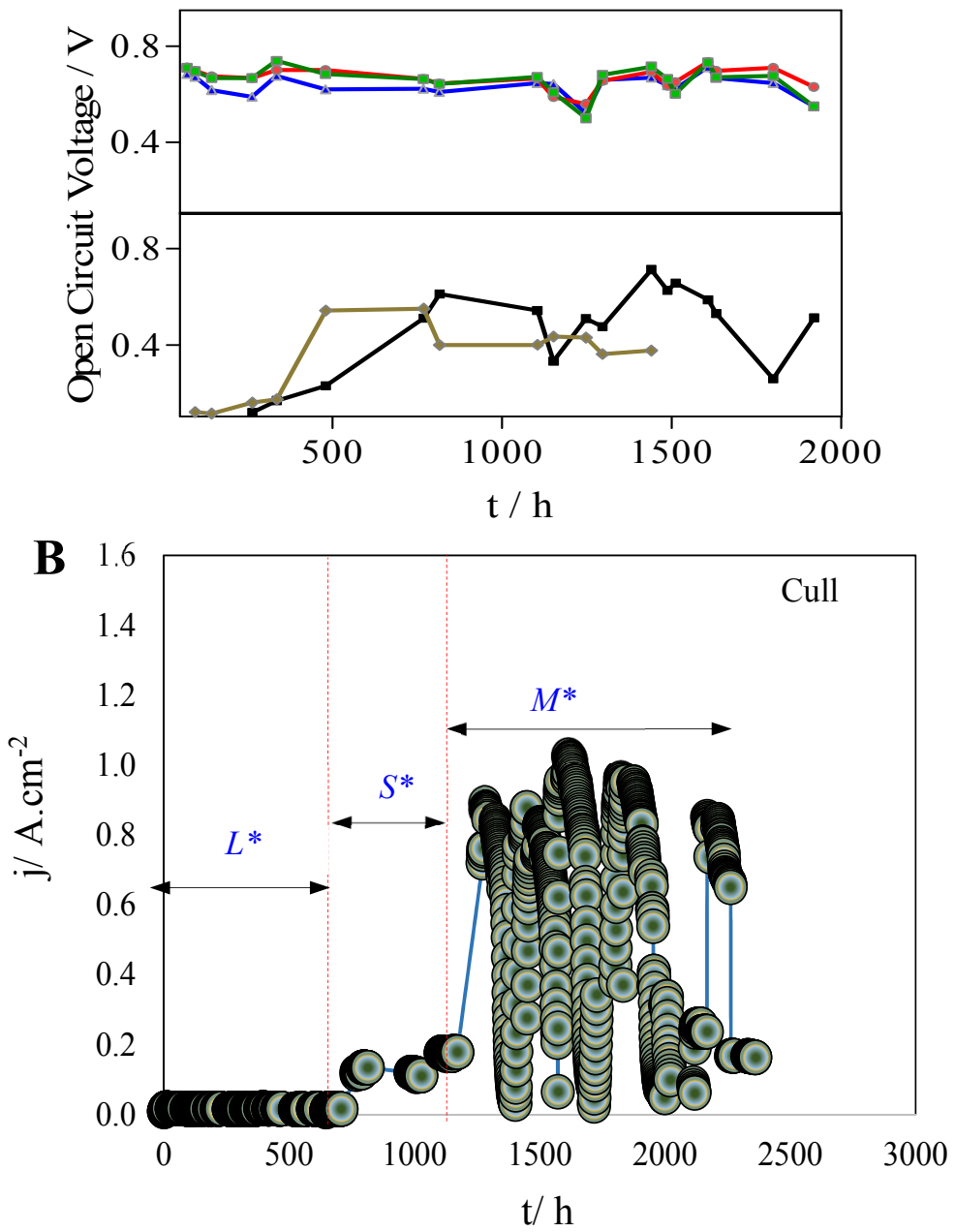

C



Fig. 2 (A) Steady state OCV response during 3000 hours of continuous fed-batch operation (Green line - - - Cull, Blue line - - -- peel \& seed, red line - - - dextrose, black line $\rightarrow-$ Acetate and grey line $-\rightarrow-$ Wastewater) (B) steady state electrical performance with cull under closed circuit (C) steady state electrical performance of peel \& seed

(NOTE: $L^{*}$ - Lag time, $S^{*}$ - Start output, $M^{*}$ - Maximum output. See Fig. S3. for start-up of MESs with soluble substrates (dextrose, acetate, and municipal wastewater). 

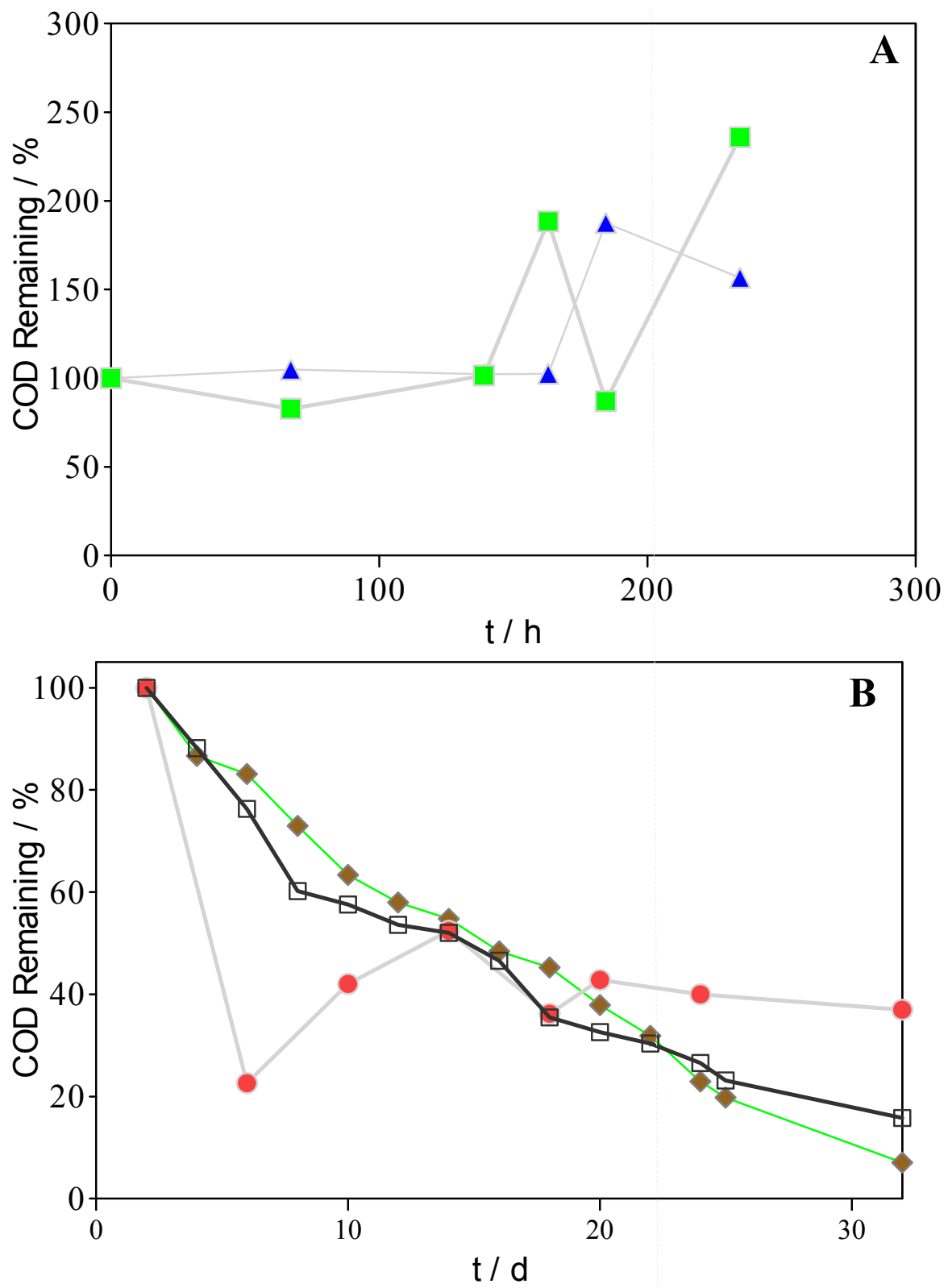

Fig. 3. (A) Remaining chemical Oxygen Demand (sCOD) in MESs with solid substrates (cull (green squares -- ) and peel \&seed (blue triangles - )). (B) sCOD remaining in MESs with wastewater (brown diamonds - ), dextrose ( red circles $-\bullet$ ), and acetate (black squares $\square$ - $(\mathrm{SD}<5 \%$; $=3$ ) 


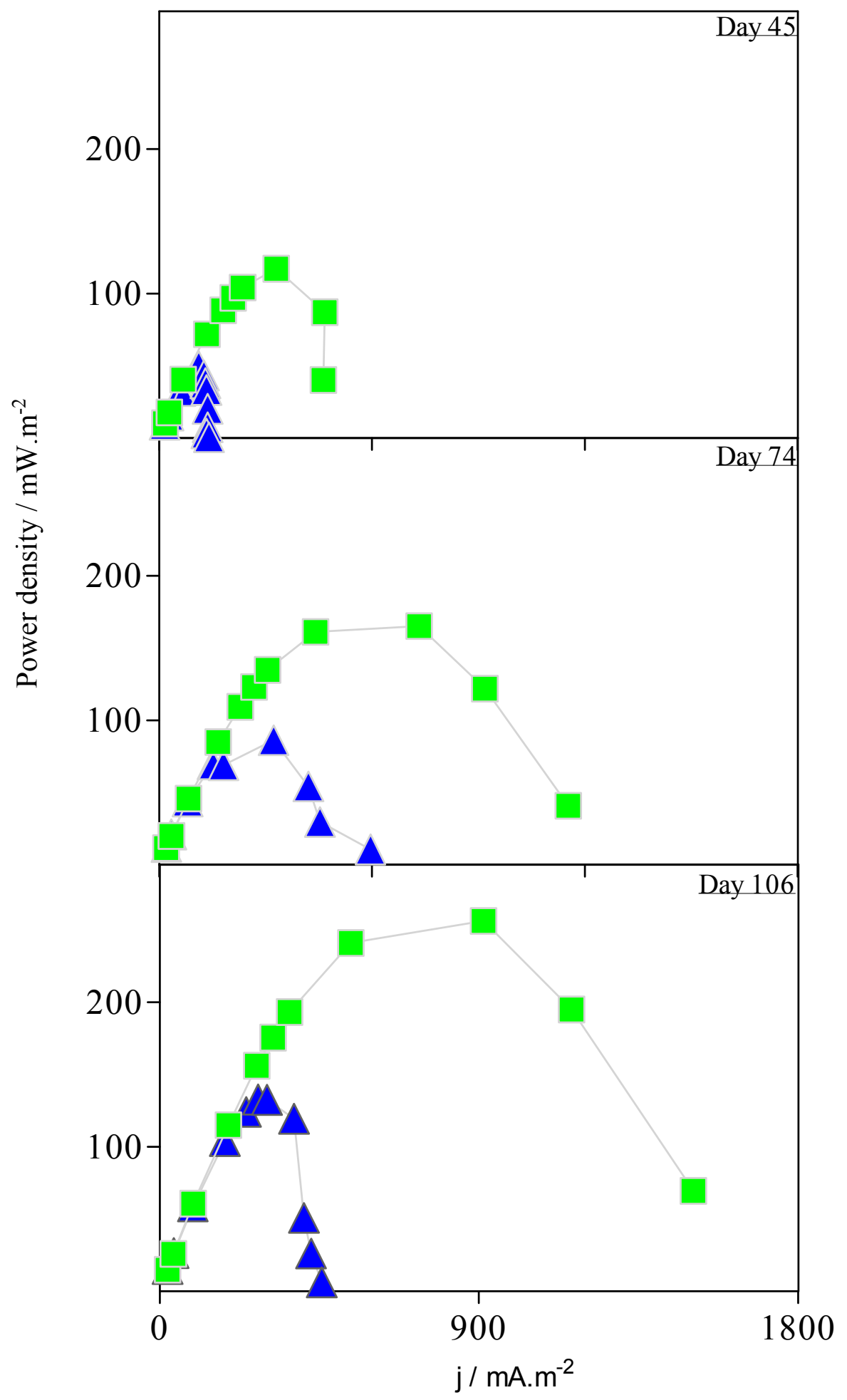

Fig. 4. Temporal data for power densities and polarization in MESs with two solid substrates (culls (green squares - - ) and peel \& seed (blue triangles $-\boldsymbol{\Lambda}$ )

NOTE: Media replacements were performed on Days 12, 27, 43,47, 53, 60, 67, 74, 84, 89, 95, and 103. See Fig. S5 for details. 


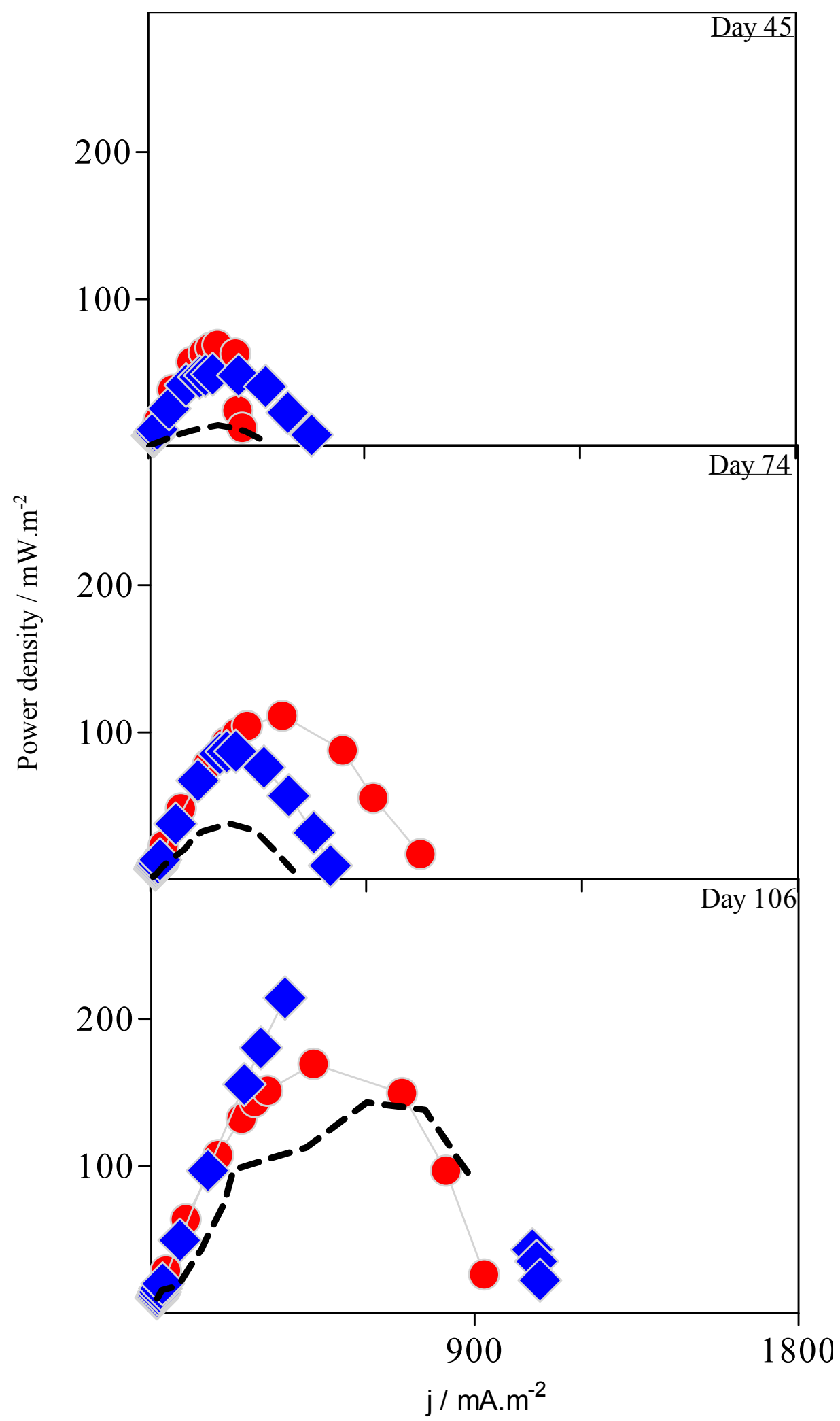

Fig. 5. Temporal data for power densities and polarization in MESs with three soluble substrates (dextrose (red circles $-\bullet$ ), acetate (blue diamonds - ), and wastewater (black dotted line - - -)

NOTE: Media replacements were performed on Days 12, 27, 43,47, 53, 60, 67, 74, 84, 89, 95, and 103. See Fig. S6 for details. 

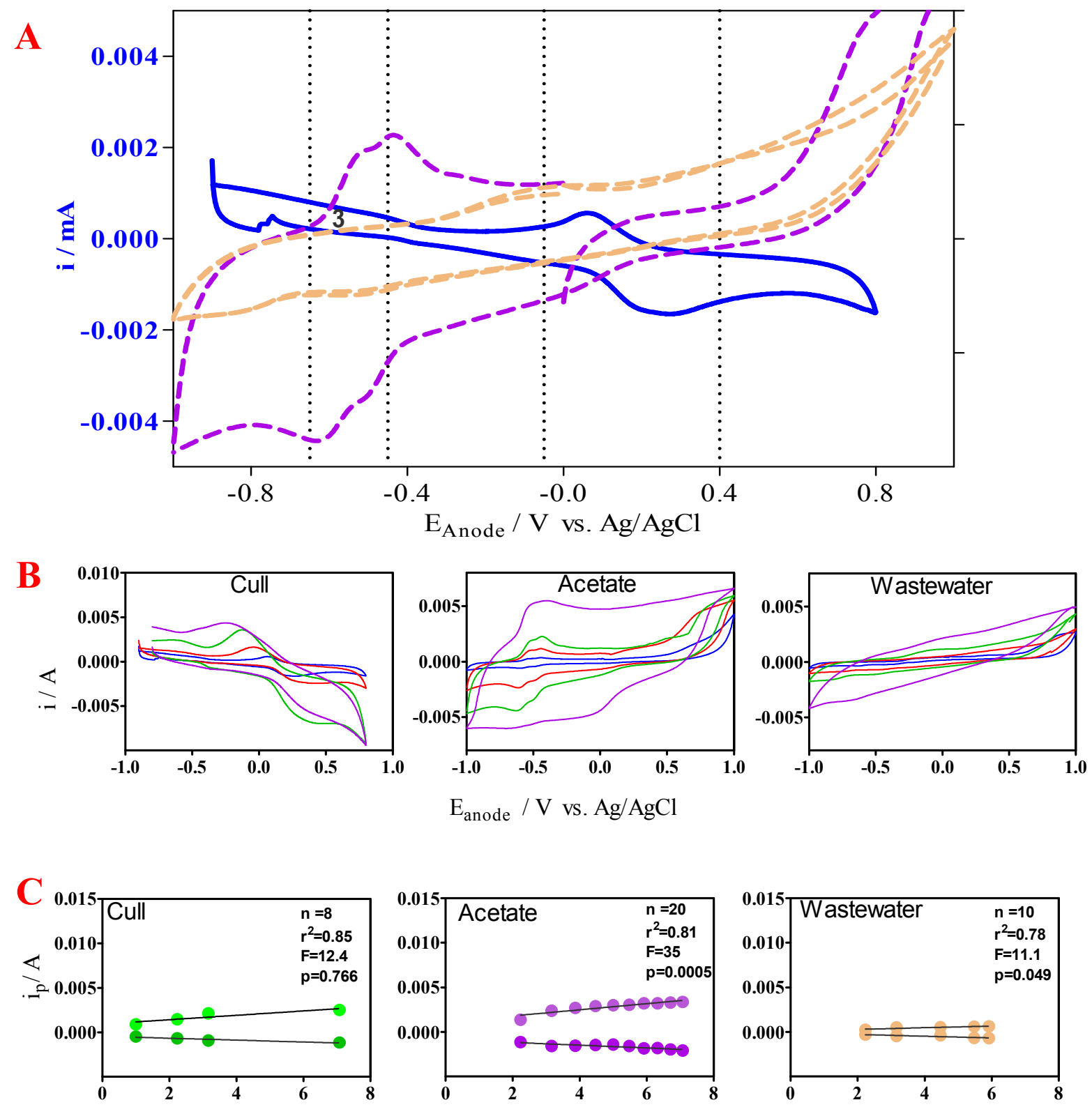

$\left(v / m v \cdot s^{-1}\right)^{0.5}$

Fig. 6. A) Cyclic voltammograms for as is culls (blue solid line - - ), acetate (purple dotted line - - -), and soluble chemical oxygen demand in municipal wastewater (dotted brown line - - -) B) Cyclic voltammograms with varying scan rates for three test MESs (blue line -- $1 \mathrm{mv} / \mathrm{s}$, redline $--5 \mathrm{mv} / \mathrm{s}$, greenline $--10 \mathrm{mv} / \mathrm{s}$, purple line - $50 \mathrm{mv} / \mathrm{s}$ ) C) Peak current against the square root of the scan rate for three test MESs (solid circles, -cull, - acetate and -wastewater) represent measured value and the black solid line represents fitted data). The CVs were generated after 365 days of fed-batch operation. Prior to obtaining CVs, the anolyte was totally drained, and washed with phosphate buffer two times. 


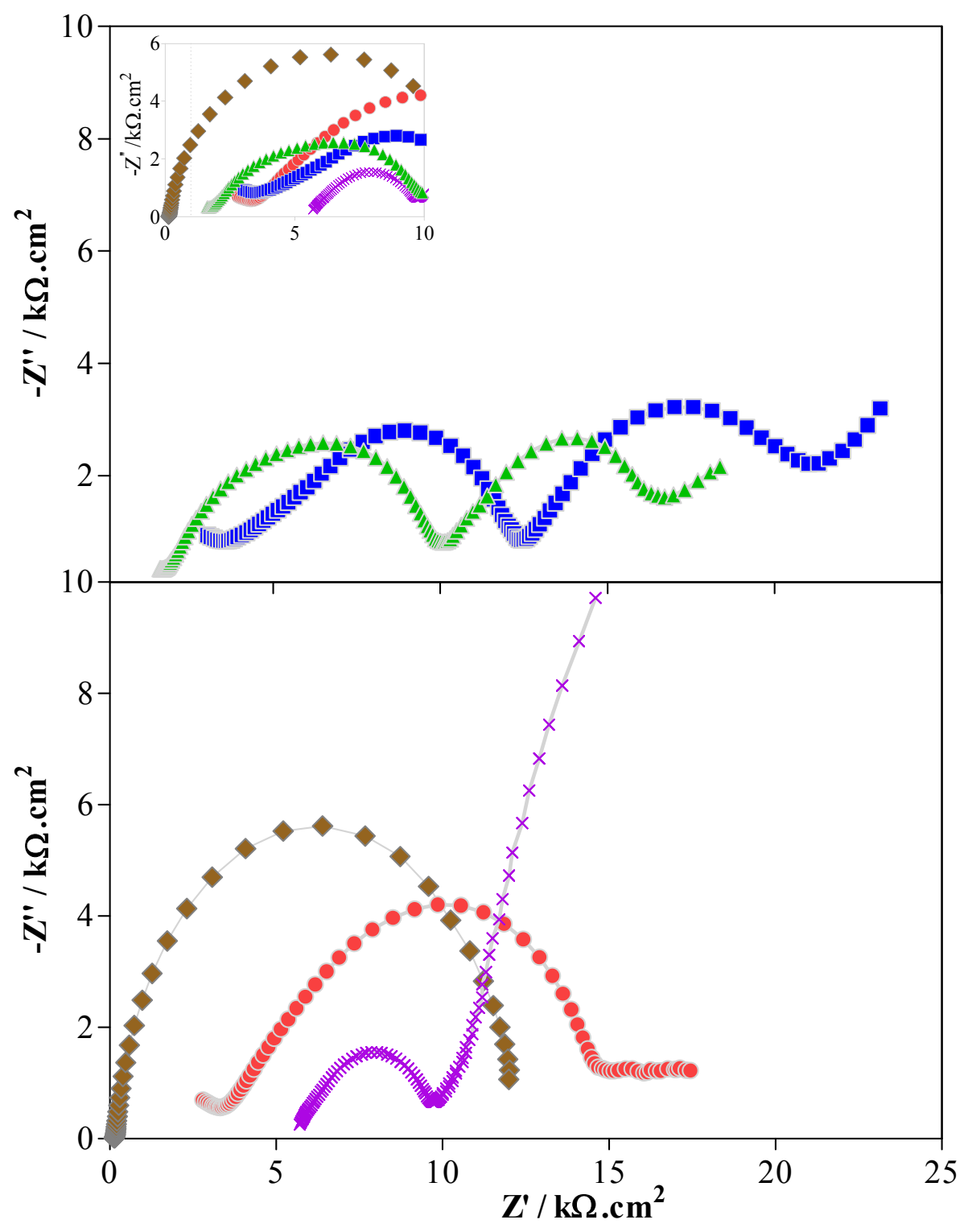

Fig. 7. Nyquist plots for MESs with wastewater (brown diamonds - - ), dextrose (red circles $-\bullet$ ), acetate ( purple cross $\rightarrow$ ), peel \& seed (blue squares--), and as is solid culls (green triangles $-\llcorner-$ ). Inset graph shows a clear view of the high frequency region. 


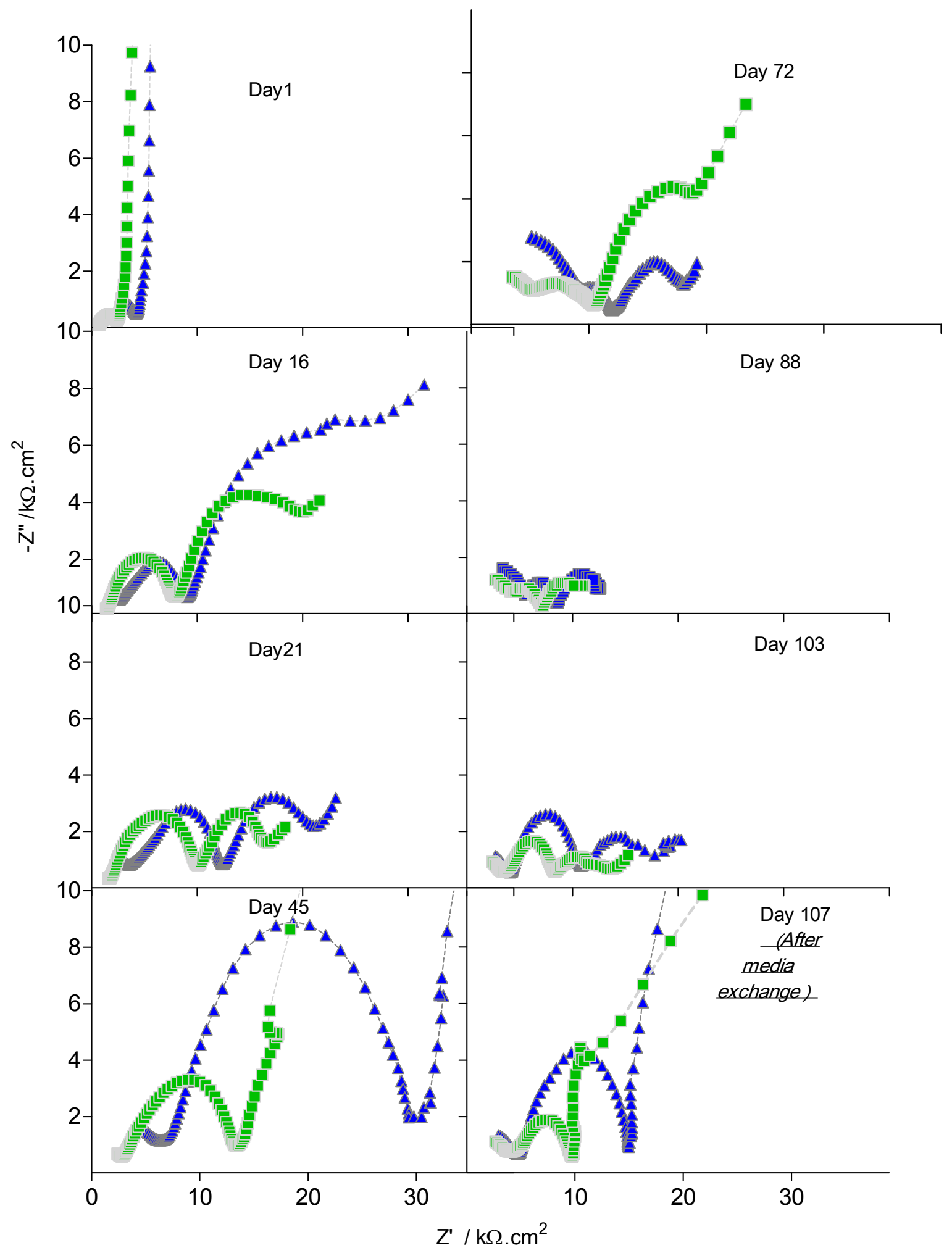

Fig. 8. Comparative Nyquist responses for MES with peel and seed (blue triangles $-\boldsymbol{-}$ ), and cull (green squares - - ) , for 100 days of fed-batch operation. AC signal: Frequency $=10 \mathrm{kHz}-100 \mathrm{mHz}$; Amplitude $= \pm 10 \mathrm{mV}$. Impedance measurements were performed on a full cell configuration. 


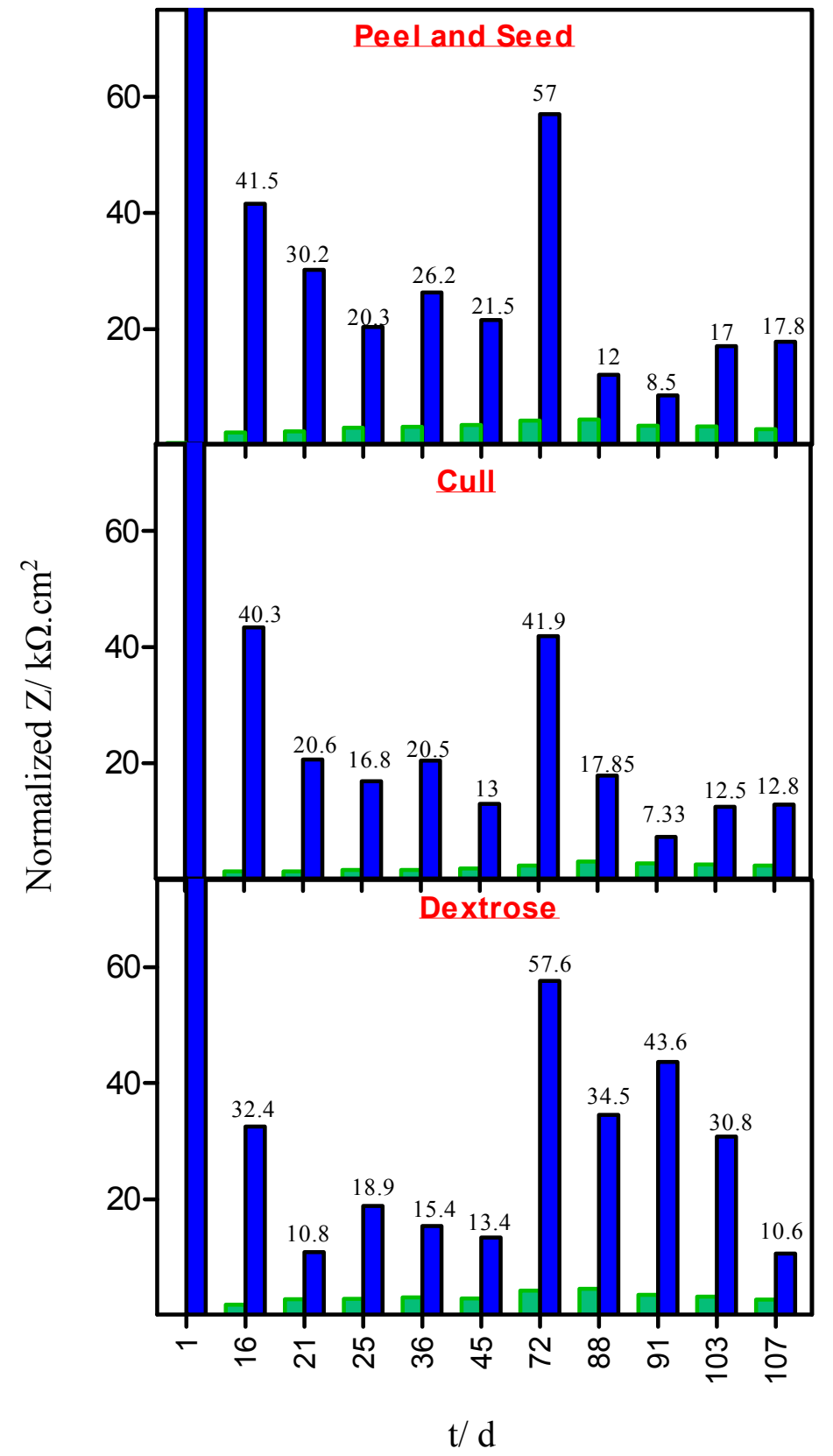

Fig. 9. Temporal changes in the ohmic losses (green bar $\square$ ) and polarization losses (blue bar $\square$ ) for: i) cull, ii) peel and seed, and iii) dextrose 


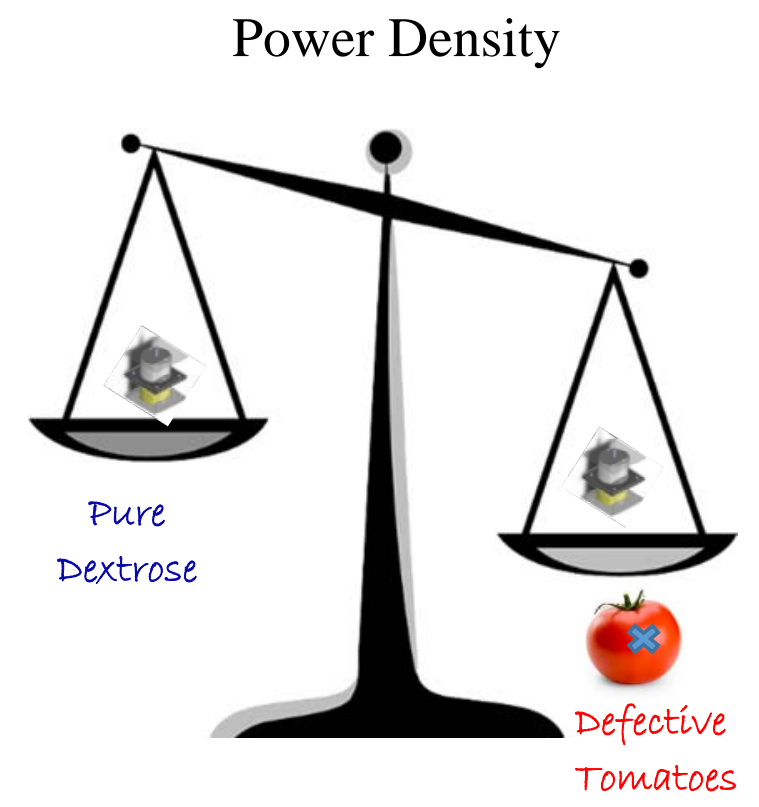

\section{Impedance Losses}

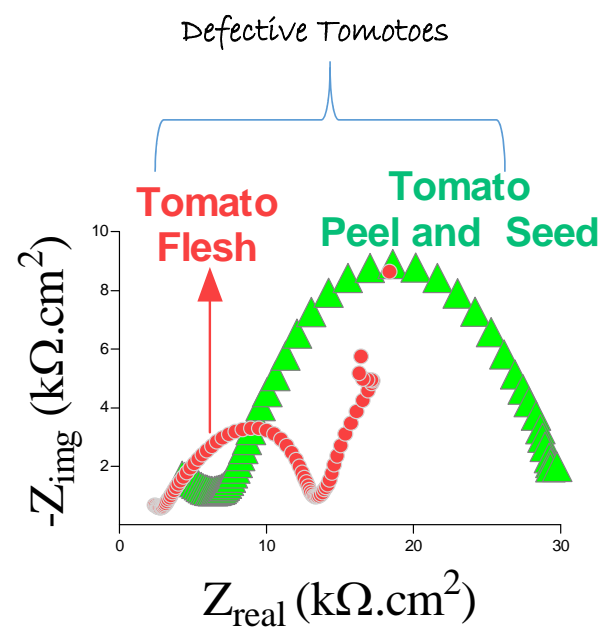

Graphical Abstract 
Table. 1a Nutritional constituents in defective tomatoes and their role in microbial electrochemical systems

\begin{tabular}{|c|c|c|}
\hline $\begin{array}{l}\text { Defective } \\
\text { Tomatoes }\end{array}$ & $\begin{array}{l}\text { Nutrition } \\
\text { Elements }\end{array}$ & Role in microbial electrochemical systems \\
\hline Cull & Sucrose & Electron donor $\left(\Delta \mathrm{G}_{\mathrm{f}}^{0}=-1,551.85 \mathrm{KJ} / \mathrm{mole}\right)^{36,67}$ \\
\hline Peel & Amino Acids & Electron donor $\left(\Delta \mathrm{G}_{\mathrm{f}}^{0}=-763 \mathrm{KJ} / \mathrm{mole}\right)^{38,67}$ \\
\hline Seed & Oleic Acid & Electron donor $\left(\Delta \mathrm{G}_{\mathrm{f}}^{0}=-50.88 \mathrm{KJ} / \mathrm{mole}\right)^{38,37}$ \\
\hline Seed & Palmitic Acid & Electron donor $\left(\Delta \mathrm{G}_{\mathrm{f}}^{0}=-305.0 \mathrm{KJ} / \mathrm{mole}\right)^{37,39}$ \\
\hline Seed & Stearic Acid & Electron donor $\left(\Delta \mathrm{G}_{\mathrm{f}}^{0}=-50.88 \mathrm{KJ} / \mathrm{mole}\right)^{37,39}$ \\
\hline Seed & Linoleic Acid & Electron donor $\left(\Delta \mathrm{G}_{\mathrm{f}}^{0}=-50.88 \mathrm{KJ} / \mathrm{mole}\right)^{37,39}$ \\
\hline Peel/Seed & $\mathrm{Cu}, \mathrm{Mn}, \mathrm{Ni}, \mathrm{Zn}$ & Microelements for bacterial metabolism ${ }^{38}$ \\
\hline $\begin{array}{l}\text { Cull/Seed/ } \\
\text { Peel }\end{array}$ & $\mathrm{Fe}, \mathrm{Na}, \mathrm{K}, \mathrm{Ca}$ & Macroelements for bacterial metabolism ${ }^{38,67}$ \\
\hline Cull & Vitamin A, C & Growth factors for bacterial metabolism ${ }^{38,67}$ \\
\hline
\end{tabular}


Table. 1b Redox-active species found in defective tomatoes, their standard reduction potential and number of electrons transferred to and from redox species

$\begin{array}{llllll} & \mathrm{E}^{\mathrm{o}} & \text { \# of } & & \\ \text { Constituents } & \text { (V vs } & \text { electron } & \text { Oxidized Species } & \text { Reduced species } & \text { Notes } \\ & \text { SHE) } & \text { transferred } & & \end{array}$

\begin{tabular}{|c|c|c|c|c|}
\hline Carotenoids & $\begin{array}{l}0.204 \text { to } \\
0.449^{74}\end{array}$ & 1 or 2 & $\begin{array}{rll}\mathrm{Car} & \rightleftarrows & \mathrm{Car}^{+} \\
\mathrm{Car}^{+} & \rightleftarrows & \mathrm{Car}^{2+} \\
\mathrm{Car}^{+} & \rightleftarrows & \mathrm{Car}\end{array}$ & $\begin{array}{l}\text { Redox potentials of cation radicals and di-cations were used to } \\
\text { elucidate reaction mechanisms for carotenoids. }{ }^{74}\end{array}$ \\
\hline Iron & $0.772^{67}$ & 1 & $\mathrm{Fe}^{2+}$ & $\begin{array}{l}\text { Iron redox mediator was described in the context of two-step } \\
\text { water splitting reaction. }{ }^{68}\end{array}$ \\
\hline Kampferol & $0.443^{42}$ & 2 & & $\begin{array}{l}\text { High-performance liquid chromatography (with UV detection) } \\
\text { was used to establish the presence of kampferol in tomatoes. } \\
\text { Redox activity of kampferol is different in aprotic medium } \\
\text { (Dimethyl sulfoxide) compared to water. Nitrogenous } \\
\text { nucleophile (e.g. imidazole) was observed to facilitate the } \\
\text { electron transfer from kampferol. }{ }^{43}\end{array}$ \\
\hline
\end{tabular}

Malvin

$0.49^{72}$

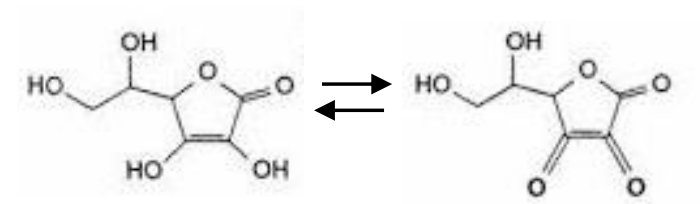

Liquid chromatography-mass spectrometry confirmed the presence of malvin in tomatoes..$^{40}$ Electronic absorption spectra revealed the structural changes of malvin, caused by $\mathrm{pH}$ changes in the medium, which appeared in its voltammetric behavior. ${ }^{44}$ 
Myricetin
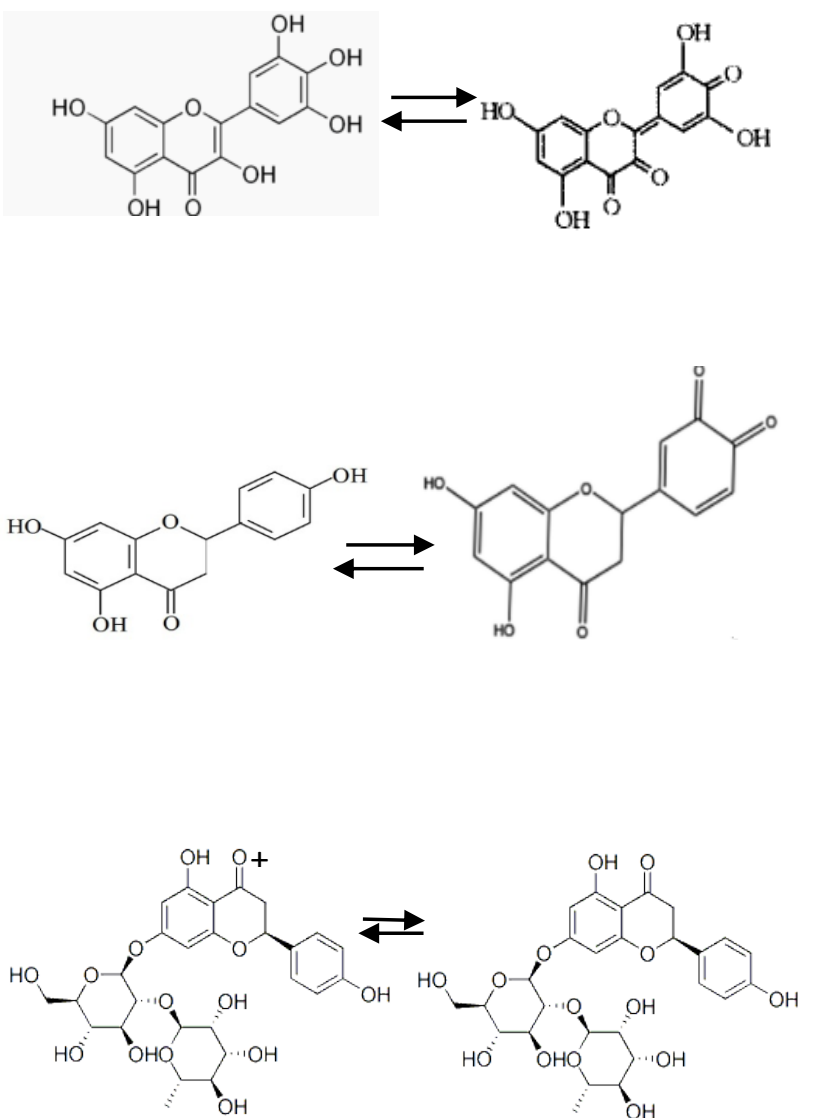

High-performance liquid chromatography with UV detection confirmed the presence of myricetin in tomatoes. ${ }^{78}$ Redox activity of myricetin is $\mathrm{pH}$ dependent because of deprotonation. The final oxidation product of myricetin adsorbs on the electrode surface and blocks electron transfer. ${ }^{45}$

Liquid chromatography-mass spectrometry with UV detection showed the presence of naringenin in tomatoes. ${ }^{41}$ The oxidation was irreversible and involved diffusion characteristics. $^{46}$

Liquid chromatography-mass spectrometry with UV detection showed the presence of naringin in tomatoes. ${ }^{41}$ The peak corresponding to the reduction of the carbonyl group in naringin became smaller with increasing $\mathrm{pH}$, finally vanishing completely in strongly alkaline solutions. Due to this, determination of naringin can be challenging. ${ }^{50}$ 


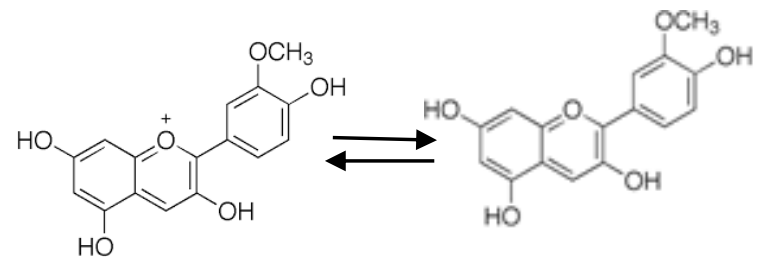

$\mathrm{HO}$
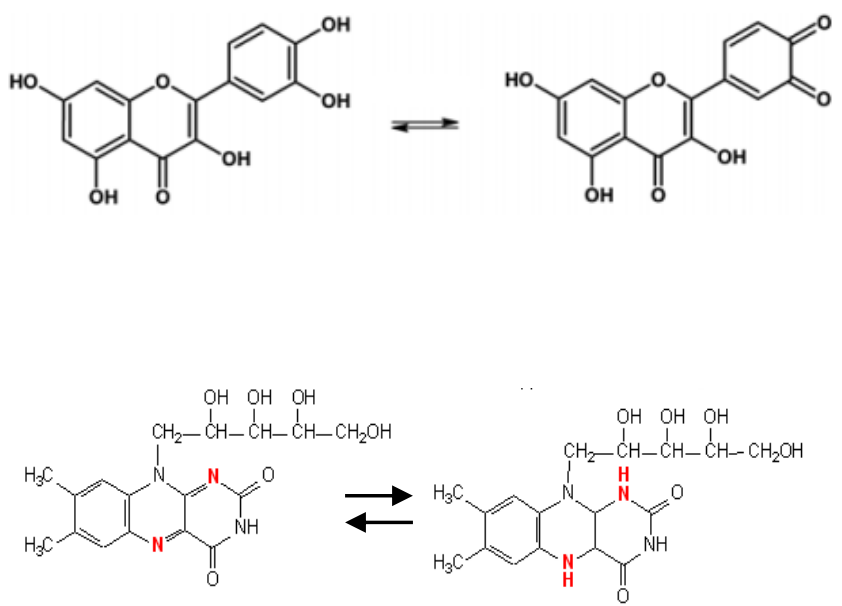

High-performance liquid chromatography with UV detection showed the presence of quercetin in tomatoes. ${ }^{78}$ Cyclic voltammetry established the electrochemical activity of quercetin in $\mathrm{pH}$ range of 4.3 to $11.2 .^{51}$

Liquid chromatography-mass spectrometry showed the presence of petunidin in tomatoes. ${ }^{40}$ Hydroxyl groups of petunidin can be electrochemically oxidized. This oxidation is $\mathrm{pH}$ dependent process, with the occurrence of adsorption and of oxidation products blocking the electrode surface. ${ }^{47}$

Riboflavins are ubiquitously found in tomatoes. ${ }^{29}$ Riboflavin molecules impart extracellular respiratory capabilities in Shewanella oneidensis. ${ }^{66}$ 
Rutin

$0.35^{40}$
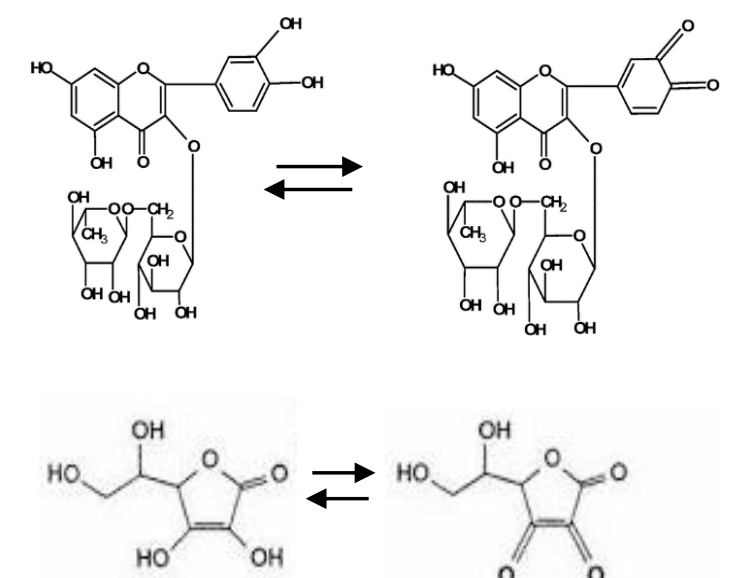

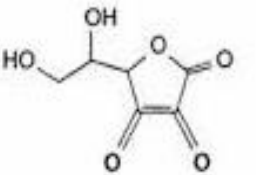

2
Liquid chromatography-mass spectrometry with UV detection showed the presence of rutin in tomatoes. ${ }^{41}$ The

electrochemical oxidation involves a complex process-first, it is oxidized by a two-electron - two-proton reversible

oxidation reaction, followed by an irreversible oxidation

reaction due to the 5,7-dihydroxyl group. Both mechanisms are $\mathrm{pH}$ dependent. ${ }^{48}$

Vitamin $\mathrm{C}$ is a ubiquitous component in tomatoes. It

facilitates electron transfer to the cytochrome $\mathrm{C}$ within the Chloroflexus aurantiacus. ${ }^{40}$ 

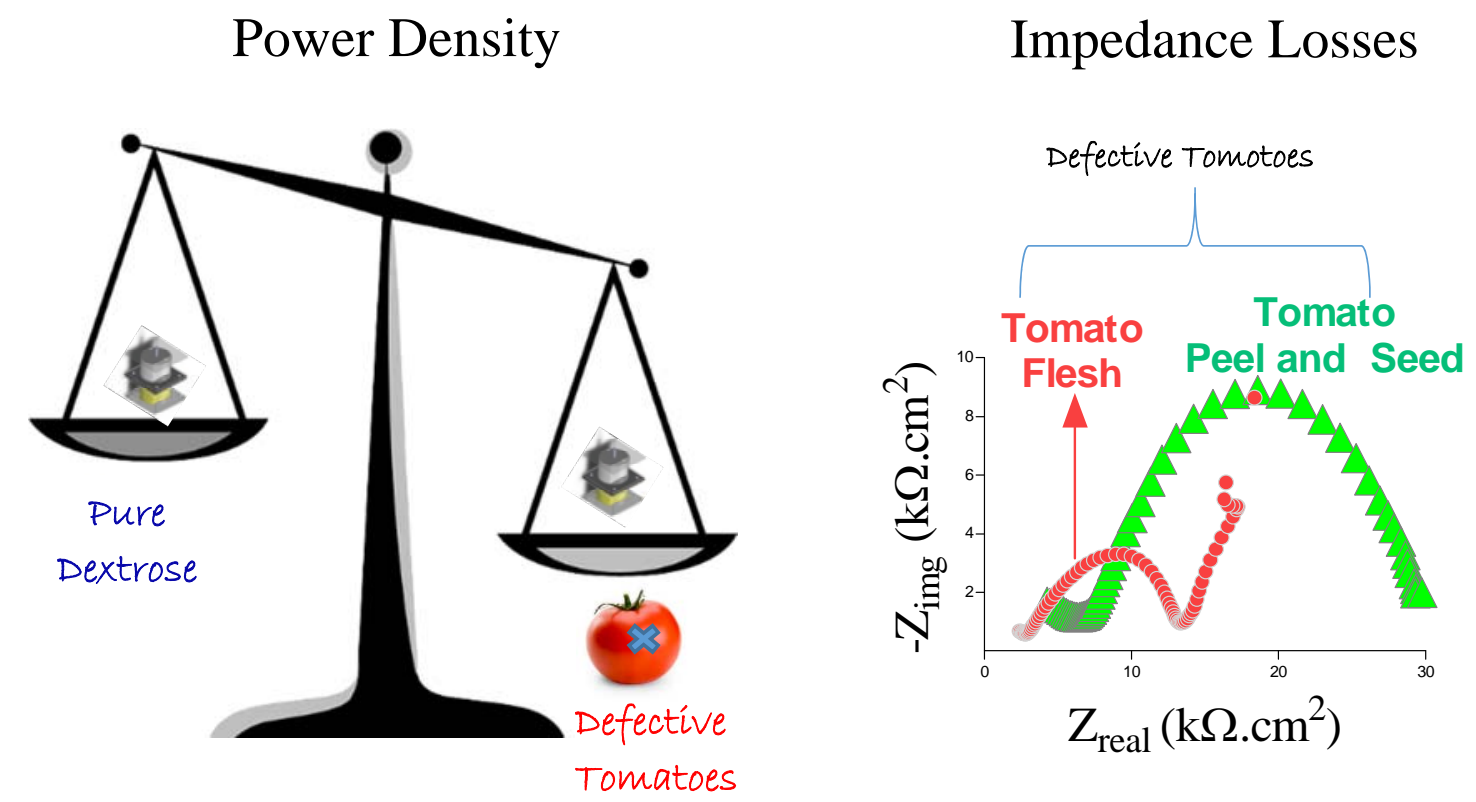

Graphical Abstract 